\title{
SPRTN protease-cleaved MRE11 decreases DNA repair and radiosensitises cancer cells
}

\author{
Juri $\mathrm{Na}^{1}$, Joseph A. Newman², Chee Kin Then ${ }^{1}$, Junetha Syed ${ }^{1}$, Iolanda Vendrell ${ }^{1,3}$, Ignacio Torrecilla $\mathbb{1}^{1}$, \\ Sophie Ellermann (1)', Kristijan Ramadan (1)', Roman Fischer ${ }^{3}$ and Anne E. Kiltie (1)
}

\begin{abstract}
The human MRE11/RAD50/NBS1 (MRN) complex plays a crucial role in sensing and repairing DNA DSB. MRE11 possesses dual $3^{\prime}-5^{\prime}$ exonuclease and endonuclease activity and forms the core of the multifunctional MRN complex. We previously identified a C-terminally truncated form of MRE11 (TR-MRE11) associated with post-translational MRE11 degradation. Here we identified SPRTN as the essential protease for the formation of TR-MRE11 and characterised the role of this MRE11 form in its DNA damage response (DDR). Using tandem mass spectrometry and site-directed mutagenesis, the SPRTN-dependent cleavage site for MRE11 was identified between 559 and 580 amino acids. Despite the intact interaction of TR-MRE11 with its constitutive core complex proteins RAD50 and NBS1, both nuclease activities of truncated MRE11 were dramatically reduced due to its deficient binding to DNA. Furthermore, lack of the MRE11 C-terminal decreased HR repair efficiency, very likely due to abolished recruitment of TR-MRE11 to the sites of DNA damage, which consequently led to increased cellular radiosensitivity. The presence of this DNA repair-defective TR-MRE11 could explain our previous finding that the high MRE11 protein expression by immunohistochemistry correlates with improved survival following radical radiotherapy in bladder cancer patients.
\end{abstract}

\section{Introduction}

MRE11 is a component of the conserved MRE11-RAD50-NBS1 (MRN) complex, a key player in the early stages of the DNA damage response (DDR). MRN is responsible for the recognition, repair, and signalling of DNA double-strand breaks (DSB) $)^{1,2}$ and is required for homologous recombination (HR), classical non-homologous end-joining (C-NHEJ) and alternative non-homologous end-joining (A-NHEJ) pathways in detection and signalling of DSBs ${ }^{3}$. Its effects are mediated via its $3^{\prime}-5^{\prime}$ exonuclease and single-stranded (ss) and DNA hairpin endonuclease activities ${ }^{4-7}$. Absence of any of its components leads to embryonic lethality in mammals ${ }^{4}$. The $3^{\prime}-5^{\prime}$ exo- and endonuclease activities of

Correspondence: Anne E. Kiltie (anne.kiltie@oncology.ox.ac.uk) ${ }^{1}$ MRC Oxford Institute for Radiation Oncology, Department of Oncology, University of Oxford, Oxford OX3 7DQ, UK

${ }^{2}$ Centre for Medicines Discovery, University of Oxford, Oxford, UK Full list of author information is available at the end of the article Edited by R. Aqeilan
MRE11 have specialised roles in HR repair and in supporting ataxia-telangiectasia-mutated and Rad3- related (ATR) kinase activation ${ }^{8,9}$. Abrogation of MRE11 nuclease activity causes a striking array of phenotypes, indistinguishable from the absence of MRN, including early embryonic lethality and marked genomic instability ${ }^{2,9}$. Inherited MRE11 mutations cause symptoms very similar to the disease ataxia telangiectasia ${ }^{10-12}$.

We previously identified a C-terminally truncated form of MRE11 (TR-MRE11) which is generated posttranslationally ${ }^{13}$. Here we investigate the cleavage site of TR-MRE11, its effects on DNA damage repair following ionising radiation and the likely associated protease. Having identified the putative cleavage site, we successfully established stable TR-MRE11 cell lines and produced recombinant truncated protein. TR-MRE11 lacked nuclease activity and DNA binding efficiency whilst still interacting efficiently with RAD50 and NBS1, thus likely maintaining an intact MRN complex structure lacking the MRE11 C-terminus. Cells expressing TR-MRE11 had

\section{(c) The Author(s) 2021}

(c) (i) Open Access This article is licensed under a Creative Commons Attribution 4.0 International License, which permits use, sharing, adaptation, distribution and reproduction cc) in any medium or format, as long as you give appropriate credit to the original author(s) and the source, provide a link to the Creative Commons license, and indicate if changes were made. The images or other third party material in this article are included in the article's Creative Commons license, unless indicated otherwise in a credit line to the material. If material is not included in the article's Creative Commons license and your intended use is not permitted by statutory regulation or exceeds the permitted use, you will need to obtain permission directly from the copyright holder. To view a copy of this license, visit http://creativecommons.org/licenses/by/4.0/. 
deficient DNA damage repair function. Finally, we identified that the metalloprotease SPRTN as the key protease that induces TR-MRE11 accumulation.

\section{Materials and methods Cell culture}

293T cells were obtained from ATCC, Manassas, VA, in 2011, and maintained in high glucose DMEM (GibcoThermo Fisher Scientific, CA) supplemented with 10\% FBS (Thermo Fisher, Waltham, CA) without antibiotics. The cell lines RT112 and VM-CUB1 were purchased from the German Collection of Microorganisms and Cell Cultures (DSMZ), Braunschweig, Germany, and maintained in RPMI medium (MilliporeSigma, Burlington, MA) or DMEM medium (Gibco, Thermo Fisher Scientific, Waltham, MA), respectively supplemented with $10 \%$ FBS without antibiotics. Cells were maintained at $37^{\circ} \mathrm{C}$ and $5 \% \mathrm{CO}_{2}$ in a humidified incubator. 293T cells were confirmed to be mycoplasmanegative by PCR in January 2019. RT112 wildtype, RT112MRE11 KD, and RT112-full length MRE11 were confirmed to be mycoplasma negative by PCR in September 2018. VMCUB1 wildtype, VM-CUB1-MRE11 KD, and VM-CUB1-full length MRE11 were confirmed by MycoAlert (Lonza, Basel, Switzerland) in February 2020. Cell lines were used up to 30 passages from original stock, including the transfection and selection procedures.

\section{Protein digestion, LC-MS/MS and data analysis of MRE11 pull down}

RT112 cells $\left(2 \times 10^{7}\right.$ cells per dish) were plated in five $15 \mathrm{~cm}$ dishes and harvested 2 days later. Total protein concentration was determined by BCA assay (Thermo Fisher Scientific, Waltham, MA). For immunoprecipitations, $10 \mathrm{mg}$ lysate was precleared with protein A/G dynabeads (Thermo Fisher Scientific, Waltham, MA) at $4{ }^{\circ} \mathrm{C}$ for $60 \mathrm{~min}$. Lysates were incubated overnight with anti-MRE11 antibody (ab214) then added to protein A/G beads $(40 \mu \mathrm{l})$ at $4{ }^{\circ} \mathrm{C}$ for $2 \mathrm{~h}$. Beads were washed six times in PBS and binding proteins eluted by boiling for $10 \mathrm{~min}$ at $95^{\circ} \mathrm{C}$ in $40 \mu \mathrm{l} \mathrm{Laemmli} \mathrm{buffer} \mathrm{before} \mathrm{running} \mathrm{on} \mathrm{an} 4-20 \%$ SDS-PAGE gel. After instant blue staining, bands corresponding to FL- or TR-MRE11 were excised from the gel, cut into small pieces and subjected to an in-gel-digest process ${ }^{14}$. In brief, gel bands were destained, incubated with $10 \mathrm{mM}$ DTT and $50 \mathrm{mM}$ iodacetamide before incubating them with $60 \mathrm{ng}$ of trypsin or elastase overnight at $37^{\circ} \mathrm{C}$. Peptides were extracted and dried down.

Dried peptides were reconstituted in 98\% LC-MS/MS water, $2 \%$ acetonitrile and $0.1 \%$ TFA. Fifty to fifty-eight percent of the tryptic or elastase peptides were analysed over $1 \mathrm{~h}$ gradient from 2 to $35 \%$ acetonitrile in $5 \%$ dimethyl sulfoxide, $0.1 \%$ formic acid (at $250 \mathrm{nl} / \mathrm{min}$ ) using a Dionex Ultimate 3000 UPLC connected to an Orbitrap Fusion Lumos trihybrid operated in data-dependent acquisition mode (both instruments from Thermo). Data were acquired with the universal method as described previously ${ }^{15}$. Briefly, full MS scans were acquired in the Orbitrap at $120 \mathrm{k}$ resolution over a $\mathrm{m} / \mathrm{z}$ range 400-1500, AGC target of 4e5 and S-lens RF of 30. Fragment ion spectra (MS/MS) were acquired in the Orbitrap ( $15 \mathrm{~K}$ resolution) with a Quad isolation window of 1.2, AGC target of $5 \mathrm{e} 4$ and a maximum injection time of $40 \mathrm{~ms}$, with HCD activation and $28 \%$ collision energy.

MASCOT (vs2.4, Matrix Science) was used for peptide and protein identification. Data were searched against the human SwissProt database (downloaded 2017_08 for TR MRE11 and 2017_07 for FL MRE11). MASCOT results were reported after applying an ion score cut off of 20 and a $1 \%$ FDR above identity or homology threshold.

\section{Protein purification}

FL-MRE11 and TR-MRE11 constructs were cloned into pNIC28-Bsa4 and SUMO2-LIC vectors respectively by LIC cleavage. Proteins were expressed in E. coli BL21 (DE3)-R3-pRARE in Terrific Broth and were induced using IPTG $(0.1 \mathrm{mM})$ at $18{ }^{\circ} \mathrm{C}$ (OD point $\left.2-3\right)$. Cells were harvested by centrifugation. For purification, cell pellets were thawed and resuspended in buffer A (50 mM HEPES $\mathrm{pH} 7.5,500 \mathrm{mM} \mathrm{NaCl}, 5 \%$ glycerol, $10 \mathrm{mM}$ imidazole, $0.5 \mathrm{mM}$ Tris (2-carboxyethyl) phosphene (TCEP)). Cells were lysed using sonication and cell debris pelleted by centrifugation. Lysates were applied to a Ni-NTA IMAC gravity flow column (Qiagen, Hilden, Germany), washed with two column volumes of wash buffer (buffer A supplemented with $45 \mathrm{mM}$ imidazole), and eluted with the addition of $300 \mathrm{mM}$ imidazole in buffer A. For FLMRE11, the elution fraction was immediately concentrated, and gel filtration applied using a HiLoad 16/60 Superdex 200 column (GE health care, Chicago, IL). Fractions containing FL-MRE11 were harvested and cleaved with the addition of 1:20 mass ratio of TEV protease. For TR-MRE11, the purification tag was cleaved with the addition of 1:20 mass ratio of SUMO protease during overnight dialysis into buffer B (20 mM HEPES, $\mathrm{pH}$ 7.5, $500 \mathrm{mM} \mathrm{NaCl}, 5 \%$ glycerol, $0.5 \mathrm{mM}$ TCEP). SUMO was removed by IMAC column rebinding and final protein purification was performed by size exclusion chromatography using a HiLoad 16/60 Superdex 200 column in buffer $B$ at $1 \mathrm{ml} / \mathrm{min}$ in buffer B. Protein concentrations were determined by measurement at $280 \mathrm{~nm}$ (Nanodrop) using the calculated molecular mass and extinction coefficients, and intact masses were confirmed by ESI-MS. Coomassie stained gels of all constructs used in this study are shown in Fig. S4.

\section{ESI-MS mass spectrometry}

Thirty microlitre protein samples at $0.02 \mathrm{mg} / \mathrm{ml}$ in $0.1 \%$ formic acid were injected onto a $4.6 \times 50 \mathrm{~mm}$ Zorbax 
5- $\mu \mathrm{m}$ 300SB-C3 column (AG883995-909; Agilent, Santa Clara, CA) and resolved by reversed-phase chromatography at $40^{\circ} \mathrm{C}$. The solvent system was $0.1 \%$ formic acid in double distilled $\mathrm{H}_{2} \mathrm{O}$ (buffer $\mathrm{A}$ ) and $0.1 \%$ formic acid in methanol (buffer B), with 1 min at $5 \%$ buffer B and then a linear gradient of $5-95 \%$ buffer B over $6 \mathrm{~min}$ at $0.5 \mathrm{ml} /$ min. Protein intact mass was determined using an MSDTOF electrospray ionization orthogonal time-of-flight mass spectrometer (Agilent Technologies, Palo Alto, CA) operated in positive ion mode.

\section{Fluorescence polarization}

For the DNA binding assay, oligonucleotides were chemically synthesized and purified by HPLC (Eurofins Scientific, Luxembourg). The oligonucleotide sequences were: TP423 (labelled with FITC at 5'): 5'-CTG CAG GGT TTT TGT TCC AGT CTG TAG CAC TGT GTA AGA CAG GCC AGA TC-3'; and TP424: 5'-CAC AGT GCT ACA GAC TGG AAC AAA AAC CCT GCA GTA CTC TAC TCA TCT C-3'. TP423 (labelled with FITC at $\left.5^{\prime}\right)$. TP424 oligonucleotides were mixed at $50 \mu \mathrm{M}$ and heated to $96^{\circ} \mathrm{C}$ in a heat block and were allowed to cool down slowly over $2 \mathrm{~h}$ to generate the $3^{\prime}$ overhanging DNA duplexes probes. The $3^{\prime}$ overhanging DNA duplexes $(10 \mathrm{nM})$ were subsequently incubated with either purified FL-MRE11 or TR-MRE11 $(10 \mathrm{nmol} / \mathrm{L})$ proteins in the binding buffer $(10 \mathrm{mM}$ Tris at $\mathrm{pH} 8.0,25 \mathrm{mM} \mathrm{NaCl}, 0.1 \%$ Tween20, $2 \mathrm{mM}$ DTT) and fluorescence polarization measured immediately by a PHERAstar FSX (BMG Labtech, Aylesbury, UK) plate reader with excitation at $485 \mathrm{~nm}$ and emission at $520 \mathrm{~nm}$. The FP values were plotted against the log of the protein concentrations, and the apparent dissociation constants were calculated from fitting the curves with a sigmoidal four-parameter logistic binding model.

\section{Nuclease assay}

The substrate for the nuclease assay was prepared as detailed above using TP423 (labelled with FITC at 5') and TP424. Reactions $(20 \mu \mathrm{l})$ contained $100 \mathrm{nM}$ DNA in HEPES buffer (25 mM HEPES at pH 7.5, $20 \mathrm{mM} \mathrm{KCl}$, $0.2 \%$ Tween-20, $2 \mathrm{mM} \mathrm{DTT}$, and $5 \mathrm{mM} \mathrm{MnCl}_{2}$ ). After incubation for $5 \mathrm{~min}$ at $37^{\circ} \mathrm{C}$, the indicated amounts of FL-MRE11 and TR-MRE11 were added, and incubation was continued for $2 \mathrm{~h}$ at $37^{\circ} \mathrm{C}$. Reaction products were run for $2 \mathrm{hr}$ at $200 \mathrm{~V}$ on a $14 \%$ polyacrylamide gel with $8 \mathrm{M}$ urea in $1 \times$ TBE. Gels were visualised at $488 \mathrm{~nm}$ using ChemiDoc (BioRad, Hercules, CA).

\section{Transfection}

RT112-MRE11 KD cells and VM-CUB1-MRE11 KD cells were generated using psilencer-2.1-U6 neo (\#5764; Thermo Fisher, Waltham, MA), as per the manufacturer's recommendations. The shMRE11 sequences were as follows: shMRE11 forward; 5'-GAT CCG AAC CTG GTC CCA GAG GAG TTC AAG AGA CTC CTC TGG GAC CAG GTT CTT TTT TGG AAA-3'; and shMRE11 reverse; 5'-AGC TTT TCC AAA AAA GAA CCT GGT CCC AGA GGA GTC TCT TGA ACT CCT CTG GGA CCA GGT TCG-3'. After 3 days of transfection, $500 \mu \mathrm{g} /$ $\mathrm{ml}$ of G418 was added for selection with complete media (RPMI or DMEM medium supplemented with 10\% FBS for RT112 and VM-CUB1, respectively).

A lentiviral system was used to rescue full length MRE11 or truncated MRE11 expression. 293T cells were transfected in $10 \mathrm{~cm}$ dishes seeded at $5 \times 10^{6}$ cells per dish, and $9 \mu \mathrm{g}$ of either pLenti-full length MRE11 or pLenti-truncated MRE11, $4.5 \mu \mathrm{g}$ of psPAX2 (\#12260; Addgene, Watertown, MA), and $4.5 \mu \mathrm{g}$ of pMD2.G (\#12259; Addgene, Watertown, MA) were delivered to each dish with Lipofectamine 3000 (Thermo Fisher Scientific, Waltham, MA) in Opti-MEM (Thermo Fisher, Waltham, MA), according to the manufacturer's instructions. The generated lentiviral particles were collected $48 \mathrm{hr}$ following transfection and filtered through a $0.45 \mu \mathrm{m}$ syringe filter (SLHV033RS; Millipore, Burlington, MA). RT112-MRE11 KD and VM-CUB1-MRE11 KD cells were infected with the filtered lentiviral supernatant using $8 \mu \mathrm{g} / \mathrm{ml}$ of polybrene. After 3 days of infection, $5 \mu \mathrm{g} / \mathrm{ml}$ of puromycin was added for selection with complete media.

\section{lonising radiation}

RT112-wildtype, VM-CUB1-wildtype, and MRE11mutated stable cell lines were collected or fixed at various time point after various dose of Cs-137 ionising radiation (dose rate: $1.2 \mathrm{~Gy} / \mathrm{min}$ ) using a GSR-D1 irradiator (Gamma Services, Surrey, UK).

\section{Vectors and site-directed mutagenesis}

MRE11 sequences were inserted into the vector pLentipuro-CMV (P100022; Vigene, Rockville, MD). A QuickChange II XL Site-Directed Mutagenesis Kit (\#200521; Agilent, Santa Clara, CA) and XL10-Gold ultracompetent cells were used for all site-directed mutagenesis according to the manufacturers' instructions. Sanger DNA sequencing (Source Bioscience, Nottingham, UK) was used to confirm the mutated nucleotides and the deleted sequences.

\section{Homologous recombination repair assay}

DSB repair efficiency was measured as described previously ${ }^{16}$. Stable MRE11 knockdown cells were generated from U2OS-I-SceI-GFP using psilencer-2.1-U6 neo (\#5764; Thermo Fisher, Scientific, Waltham, MA), as per manufacturer's recommendations. The sequence of shMRE11 is mentioned in the 'Transfection' section of the 'Material and methods'. In brief, $2.5 \times 10^{5}$ cells were seeded onto 6-well plates and transfected with $2.5 \mu \mathrm{g}$ of 
pcDNA3.3-FL-MRE11 or pcDNA3.3-TR-MRE11 using lipofectamine 3000 , respectively. Following $24 \mathrm{~h}$ of transfection, the cells had $2.5 \mu \mathrm{g}$ of I-SceI expressing plasmid added. The cells were allowed to grow for $24 \mathrm{~h}$, followed by the measurement of GFP + cells by flow cytometry, performed on a on a BD FACS DIVA instrument (BD Biosciences, Franklin Lakes, NJ). The data were analysed by FlowJo V10. One-way ANOVA was used to determine the statistical significance of the experiments.

\section{Western blotting}

Protein lysis buffer comprised $50 \mathrm{mmol} / \mathrm{L}$ HEPES, $100 \mathrm{mmol} / \mathrm{L} \mathrm{NaCl}, 10 \mathrm{mmol} / \mathrm{L}$ EDTA, $1 \%$ Triton X-100, $4 \mathrm{mmol} / \mathrm{L} \mathrm{Na}$ pyrophosphate, $2 \mathrm{mmol} / \mathrm{L}$ sodium orthovanadate, $10 \mathrm{nmol} / \mathrm{L} \quad \mathrm{NaF}$, and $50 \mathrm{mmol} / \mathrm{L}$ Bglycerophosphate. Cells were lysed in lysis buffer containing a cocktail of proteinase inhibitors (Roche, Mannheim, Germany). Protein quantification of the lysates was performed using a BCA protein assay (Thermo Fisher, Waltham, MA) and $30 \mu \mathrm{g}$ of protein was resolved on 4-20\% polyacrylamide gels and transferred onto nitrocellulose membranes. The resulting membranes were incubated with blocking buffer (Li-cor Biosciences, Lincoln, NE) and primary antibodies. The antibodies used were anti-MRE11 (ab214; abcam, Cambridge, UK), antiMRE11 C-terminal (ab227452; abcam, Cambridge, UK), anti-MRE11 N-terminal (sc-135992; Santa Cruz, Dallas, TX), anti-myc-tag (2276 S; CST, Danvers, MA), antiphospho-histone H2A.X (Ser139) (2577; CST, Danvers, MA), anti-SPRTN (HPA025073; Atlas antibodies, Bromma, Sweden), anti-cdc25A (3652; CST, Danvers, MA), anti-pAKT (S473) (4060; CST, Danvers, MA), antiVCP(p97) (10736-1-AP; Proteintech, Rosemont, IL), and mouse monoclonal anti- $\beta$-actin (ab6276; abcam, Cambridge, UK). Fluorochrome-conjugated secondary antibodies (925-68021, 926-32210; Li-cor Biosciences, Lincoln, NE) were detected by infrared scanning densitometry using the Li-cor Odyssey Infrared Detection System (Li-cor Biosciences, Lincoln, NE).

\section{Immunoprecipitation}

Cell lysates were prepared in Pierce IP lysis buffer (Thermo; 87788). Total protein concentration was determined by BCA assay and $500 \mu \mathrm{g}$ lysate was incubated with anti-MRE11 (ab214; abcam, Cambridge, UK) at $4{ }^{\circ} \mathrm{C}$ overnight on a tube rotator and then added to protein $\mathrm{A} /$ G plus agarose (sc2003; Santa Cruz, Dallas, TX) for $1 \mathrm{~h}$ at $4{ }^{\circ} \mathrm{C}$. The beads were washed five times in PBS-Tween $0.05 \%$ and binding proteins eluted by boiling $\left(95^{\circ} \mathrm{C}\right.$ for $10 \mathrm{~min})$ in $40 \mu \mathrm{L}$ Laemmli buffer before SDS-PAGE gel running. Ten percent of the total lysate was retained as the load fraction. The antibodies used were anti-MRE11 (ab30725; abcam, Cambridge, UK), anti-RAD50 (3427; CST, Danvers, MA), anti-NBS1 (NB100-143; Novus
Biological, Centennial, CO), anti-myc-tag (2278, CST, Danvers, MA). To isolate SPRTN-interacting proteins, whole cell lysates were prepared in lysis buffer $(50 \mathrm{mM}$ Tris- $\mathrm{HCl} \mathrm{pH} 7.4 ; 150 \mathrm{mM} \mathrm{NaCl} ; 0.1 \% \mathrm{NP}-40 ; 1 \mathrm{mM}$ EDTA, and 5\% glycerol; protease and phosphatase inhibitors) containing $500 \mathrm{U} / \mathrm{ml}$ of benzonase at $4{ }^{\circ} \mathrm{C}$. Flag-tag protein complexes were separated using the anti-flag M2 antibody (F1804; Merck, Whitehouse Station, NJ) and washed five times in IP buffer containing $0.05 \%$ NP-40 and eluted in 3xFlag peptide (F4799; Merck) for 30 min at RT.

\section{Clonogenic assay}

Established stable cell lines were plated in 6-cm culture dishes containing $4 \mathrm{ml}$ of fresh medium with appropriate numbers in triplicate irradiated at $0-8$ Gy on the day after cell plating and then incubated for 2 weeks. Cells were stained with crystal violet staining solution $(0.5 \%)$ in $80 \mathrm{ml}$ distilled water, $20 \mathrm{ml}$ methanol and $0.5 \mathrm{~g}$ crystal violet powder (Merck, Whitehouse Station, NJ). Colonies containing more than 50 cells were counted and the surviving fraction was determined as the total number of colonies formed divided by the total number of cells plated multiplied by the plating efficiency, as determined in untreated cells.

\section{Cell cycle and apoptosis analysis}

For cell cycle analysis, cells were seeded in $10-\mathrm{cm}$ culture dishes at a density of $3 \times 10^{6}$ cells/dish. After $24 \mathrm{~h}$, two different doses of radiation ( $1 \mathrm{~Gy}, 5 \mathrm{~Gy}$ ) were applied and cells were incubated for $16 \mathrm{~h}$. Cells were rinsed with PBS, harvested with $0.05 \%$ trypsin, and fixed in $70 \%$ ethanol overnight. Cells were stained with $25 \mu \mathrm{g} / \mathrm{ml}$ propidium iodide (PI) in $3.3 \mu \mathrm{g} / \mathrm{ml}$ ribonuclease $\mathrm{A}$ and $0.25 \%$ triton X-100, and analysed on a FACS flow cytometer (BD FACSCalibur, BD Biosciences).

FITC Annexin V (cat no. 556547, BD Pharmingen, San Diego, CA) was used to quantitatively determine the percentage of cells undergoing apoptosis according to the manufacturer's instruction. Established stable cell lines were plated in $10-\mathrm{cm}$ culture dishes containing $10 \mathrm{ml}$ of fresh medium in appropriate numbers, irradiated to 4 and 8 Gy the day after cell plating and then incubated for $48 \mathrm{~h}$ before harvest.

\section{Immunofluorescence}

Established stable cell lines were plated onto 8-well chamber slides (734-2050; NUNC, Roskilde, Denmark) and fixed with $100 \%$ methanol for $5 \mathrm{~min}$ at $-20^{\circ} \mathrm{C}$, at each time point after IR. Cells were then washed for $5 \mathrm{~min}$ three times in PBS. All subsequent steps were carried out at room temperature. Samples were blocked for $30 \mathrm{~min}$ in blocking buffer (1\% BSA, $22.52 \mathrm{mg} / \mathrm{ml}$ glycine in PBST (PBS $+0.1 \%$ Tween 20)). Rabbit anti-phospho-histone 
H2A.X (Ser139) (\#2577; CST, Danvers, MA) and mouse anti-MRE11 (ab214; abcam, Cambridge, UK) were diluted 1:800 and 1:500, respectively in PBST and incubated overnight at $4{ }^{\circ} \mathrm{C}$. Cells were washed with PBS, after which secondary antibodies [AlexaFluor 568 (A11036) and AlexaFluor 488 (A21202; Thermo Fisher Scientific, Waltham, MA)] were diluted 1:2000 in PBST and applied for $1 \mathrm{~h}$ at room temperature. Cells were washed with PBS as before and mounted using proLong diamond antifade mountant with DAPI (P36962; Thermo Fisher Scientific, Waltham, MA). Cells were visualised for $\gamma \mathrm{H} 2 \mathrm{AX}$ immunostaining using confocal microscopy (Zeiss 710; Zeiss, Oberkochen, Germany).

\section{RNA interference and plasmid transfection}

\section{siRNA for SPRTN (5'-GUCAGGAAGUUCU} GGUUAA- $\left.3^{\prime}\right)^{17}$ transfections were performed using Lipofectamine RNAiMax reagent (Thermo Fisher Scientific, Waltham, MA) according to the manufacturer's instructions. Depletion was assayed $72 \mathrm{~h}$ posttransfection. For SPRTN overexpression, both pcDNA3.1-flag-SPRTN WT and SPRTN E112A plasmids were used for transfection and this was performed using Lipofectamine 3000 reagent (Thermo Fisher Scientific, Waltham, MA) according to the manufacturer's instructions. Overexpressed SPRTN levels were assayed $16 \mathrm{~h}$ post-transfection.

\section{In vitro cleavage of MRE11}

Recombinant SPRTN wt or E112A mutant were purified from $E$. coli as detailed in ref. ${ }^{18}$. Commercial MRE11A (NM_005590) human recombinant protein was purchased from Origene (Rockville, MD). Cleavage reactions were performed in a $25 \mu \mathrm{L}$ volume containing $500 \mathrm{ng}$ MRE11, $2 \mu \mathrm{g}$ SPRTN, and a $100 \mathrm{bp}$ dsDNA oligonucleotides (30:1 molar ratio SPRTN:dsDNA) in cleavage buffer $(25 \mathrm{mM}$ Tris, $\mathrm{pH} 7.4 ; 150 \mathrm{mM} \mathrm{NaCl})$ at $37^{\circ} \mathrm{C}$ for overnight $(>16 \mathrm{~h})$. The reaction was stopped by the addition of Laemmli buffer and boiling and used immediately.

\section{Quantification and statistical analysis}

Counting of $\gamma \mathrm{H} 2 \mathrm{AX}$ foci was determined using Image $\mathrm{J}$ software. For clonogenic assays, the surviving fraction was calculated on the basis of the number of colonies on nonirradiated plates. Data are presented as the log of the surviving fraction with error bars representing the SEM. Radiation survival curves were plotted in GraphPad Prism 8 , using the linear-quadratic model with the equation SF $=\exp -\left(\alpha D+\beta D^{2}\right)$, where $D$ is a dose of radiation. The FP values were plotted against the log of the protein concentrations, and the apparent dissociation constant calculated from fitting the curves with a sigmoidal fourparameter logistic binding model in GraphPad Prism 8.
Spearman's correlation value was acquired through ImageJ with colocalisation plugins, and $\mathrm{P}$ values for one-way ANOVA multiple comparison was calculated in GraphPad Prism 8. The levels and correlation between SPRTN and TR-MRE11 were calculated using a 2-way ANOVA multiple comparison and correlation, respectively, in GraphPad Prism 8.

\section{Results}

MRE11 in primary bladder tumours shows a truncated form which lacks the C-terminus

Having previously identified a C-terminally truncated form of MRE11 (TR-MRE11) in the bladder cancer cell line RT112, and in T24 bladder cancer cells following HDAC inhibition by panobinostat treatment ${ }^{13}$, we extended our cell line panel to include seven other bladder cancer cell lines (Fig. 1A). In cell-free extracts taken from primary bladder tumours at transurethral tumour resection, we also found the presence of the truncation in tumour samples from bladder cancer patients, but this was not associated with clinical stage (Ta, T1 and $\mathrm{T} 2$ ) (Fig. 1B).

We used two different antibodies against MRE11, which bind to the central (ab214, 182-582aa) or C-terminal regions (ab30725; 650aa-C-term) of full length MRE11, respectively, to further elucidate the truncated phenotype (Fig. 1C). TR-MRE11 was not detected with the antibody ab30725 which targets an epitope in the C-terminal domain in either RT112 or VM-CUB1 cell lines. However, both forms were detected by the antibody ab214, targeting amino acids $182-582$ in RT112 but not in VM-CUB1 cells (Fig. 1D). This indicate that TR-MRE11 does not include the C-terminal region of MRE11, and not all cell lines express TR-MRE11 forms at baseline.

Previously, our group demonstrated the existence of TR-MRE11 by mass spectrometric analysis ${ }^{13}$. To identify the MRE11 truncation locus, we optimised the MRE11 pull down by increasing the initial amount of protein and repeated the mass spectrometry experiment using two different proteases (trypsin and elastase), in order to maximise protein sequence coverage (Fig. 1E). There was $71 \%$ protein sequence coverage following trypsin digestion and $71 \%$ coverage after elastase digest of the upper band representing FL-MRE11 (Fig. 1E-ii, iii). In the lower MW band, we detected peptides covering MRE11 without the C-terminus (31\% and 38\% coverage between 1 and 538 aa, respectively), with no coverage of sequence between 539 and 708 aa (Fig. 1E-iv, v). The confidence in protein identification, as represented by sequence coverage and emPAI, is shown in Table S1. We hypothesised that the putative cleavage site (PCS) of MRE11 would lie in the region between amino acid 539 and amino acid 600 for the following reasons: (1) Assuming that the tryptic digest was complete, the arginine located at amino acid 
A

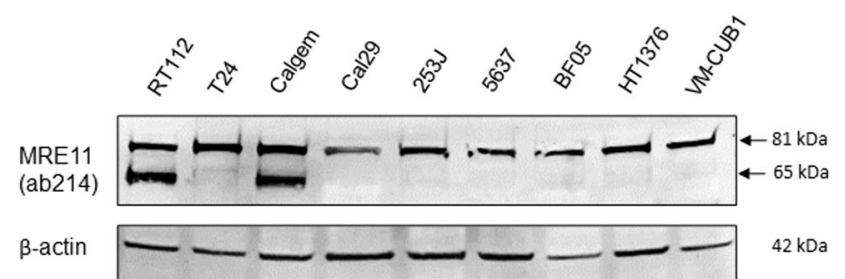

B

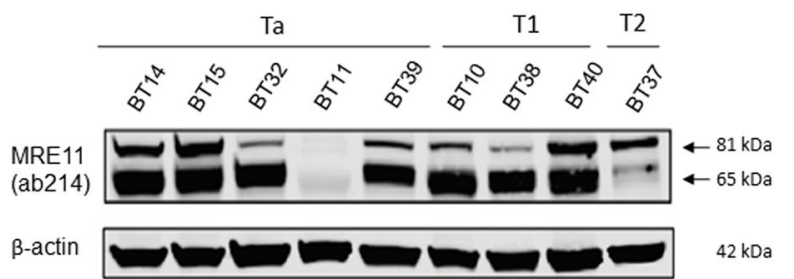

D

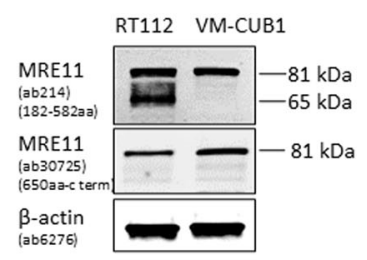

iii)

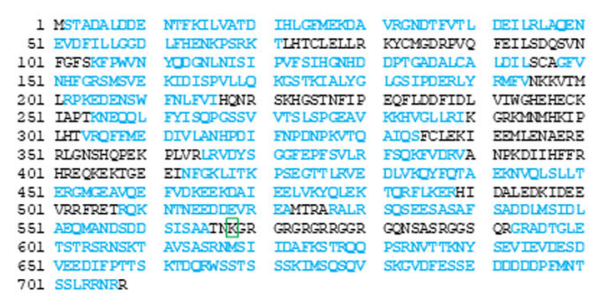

v)

iv)

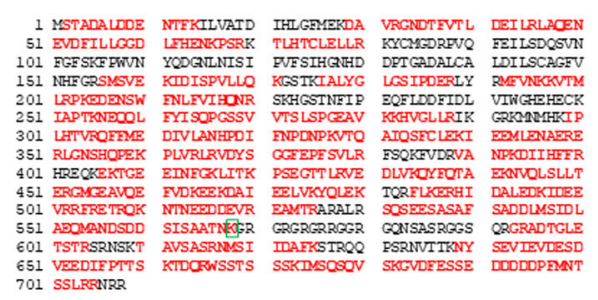

1 MSTADALDEE NTFKILVATD IHLGRERTA VRGNDTEVTL DEILRLAOEN 51 EVDFILLGGD LFHENIRPSRK TLHTCIELLR KYCMGDREVQ FEILSDQSVN 101 FGFSKRPWNN YQDGILNISI PVISTHENHD DPTGADALCA LDILSCAGFV 201 LRPKEDENSW FNLFVIHONR SKHGSTNFTP EOFIDDEIDL VIWGHEHECR 251 IAPTKNECQL FYISQPGSSV VISLSPGEAV KKHVGLLLIR GRKMMMHKIP 301 LHTVRQFPME DIVLANHPDI FNPDNPKVTO AICSFCLFRT EBMIENAERE 351 RLGNSHOPEK PLVRLRVDYS GGEEPFSVLR FSCKFVRVA NPKDIIHFF

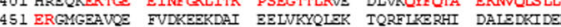
501 VRRFRETROK NTNEBDDEVR EAMTRARALR SQSEESASAF SADDIYSID S51 AZOMANDSD SISAATIGGR GRERERRGER GQNSASRQGS QRGRADTGL

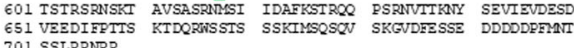

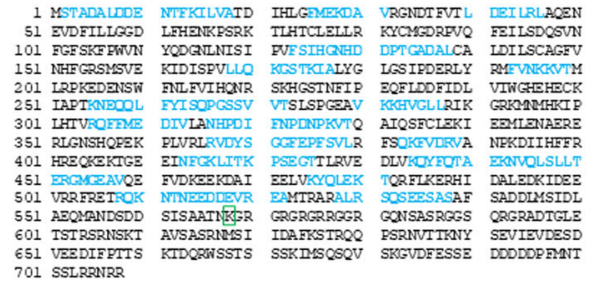

Fig. 1 MRE11 is found in truncated form in bladder cancer cell lines and primary bladder tumours. A Two out of nine bladder cancer cell lines show a truncated form of MRE11 (approximately $65 \mathrm{kDa}$ ). Calgem is gemcitabine-resistant cells created from Cal29 by exposure to increasing gemcitabine doses ${ }^{49}$. B Eight out of nine nuclear cell-free extracts from human bladder tumours show a truncated form of MRE11 (approximately $65 \mathrm{kDa}$ ). $\mathrm{Ta}=$ papillary tumour, $\mathrm{T} 1=$ tumour invading lamina propria, $\mathrm{T} 2=$ tumour invading muscularis propria. C Schematic diagram of MRE11 and the epitope regions of MRE11 of two antibodies, spanning amino from acids 182 to 582 (ab214) and 650 to C-terminus (ab30725), respectively. D In RT112, ab214, spanning amino acids 182-582, detected both FL and TR MRE11, but not in VM-CUB1. In contrast, the C-terminus anti-MRE11 antibody (ab30725) did not detect the truncated MRE11 both in RT112 and VM-CUB1. E-i The eluted sample from super-paramagnetic beads with recombinant protein A-bound MRE11 was loaded onto a precast 4-20\% polyacrylamide gel. E-ii, iii The sequence coverage of FL-MRE11 digested with trypsin (red) and elastase (blue) was $71 \%$ coverage for both cases. E-iv, $\vee$ Protein sequence coverage of TR-MRE11 digested with trypsin (red) and elastase (blue) were $23 \%$ and $28 \%$ respectively. The green box at K568 indicates the last amino acid of TR-MRE11 model.

594 would have been cleaved by trypsin to generate a peptide of 8-20 amino acid chain length detectable by Mass Spectrometry, if TR-MRE11were included that region. We, therefore, concluded that the PCS is located before MRE11 amino acid 594. (2) If TR-MRE11 were longer than $600 \mathrm{aa}$, the molecular weight of TR-MRE11 would be bigger than $68.4 \mathrm{kDa}$. However, the approximate size of TR-MRE11 on western blots was smaller than 
$67 \mathrm{kDa}$. In case the cleaving enzyme worked in a more distal region, we extended the range of the PCS to amino acid 600, rather than restricting it to amino acid 594 .

\section{The cleavage site of MRE11 is between amino acids 559 and $\mathbf{5 8 0}$}

We established a stable MRE11 KD cell line using shMRE11 and found a 5.6-fold decrease in MRE11 expression compared to WT (Fig. S1A-C).

We removed the region of the PCS, namely, amino acids 539-600 (Fig. 2A) from the MRE11 plasmid. MRE11-wt and PCS deleted (MRE11 $\triangle 539-600$ ) plasmids were independently transfected into RT112 MRE11 KD cells, and transfection efficiency determined by western blot against the C-terminal myc-tag (Fig. 2C, S2). The cleaved C-terminal part of MRE11 was detected in FL-MRE11 expressing cells but was absent in cells lacking the PCS (MRE11 $\triangle 539-600$ aa), implying that MRE11 cannot be cleaved when amino acids 539-600 are absent (Fig. 2A). In order to further specify the PCS, we designed a set of plasmids expressing various forms of MRE11 mutants, to establish stable cell lines, using a myc-tag on the Cterminal region of MRE11 (Fig. 2B). Thirty-eight cell lines from six different deletions between 539 and 600 aa were generated and representative cell lines with similar myctag expression were selected (Fig. S2). The six deletions were: $539-550$ aa, 549-560-aa, 559-570 aa, 569-580-aa, $579-590$ aa and 589-600 aa. The presence of two small fragments containing myc-tag $(\sim 20 \mathrm{kDa})$ suggested that MRE11 has two cleavage sites very near each other. The higher of the two bands $(\sim 20 \mathrm{kDa})$ was absent in the $\Delta 559-570$ aa and $\Delta 569-580$ aa deletion mutants, implying that the cleavage site is located between amino acids 559 and 580 aa (Fig. 2D). Thus, we designated $1-568$ aa as TR-MRE11 because from this experiment the cleavage site was determined to lie at $569 \pm 11$ aa and, furthermore, a run of glycine-arginine repeats started from amino acid 569. We, therefore, removed amino acids 569-708 to generate a close representation of the TR-MRE11 form in the lenti-viral vector (Fig. 2E). Of note, the level of intrinsic disorder is very high after 500 aa in MRE11, according to the predicted secondary structure of MRE11 (Fig. S3), and this could be one of the reasons why FLMRE11 is not stable at a post-translational level, allowing TR-MRE11 forms to appear.

\section{TR-MRE11 forms the intact MRN complex but lacks nuclease activity}

Its dual $3^{\prime}-5^{\prime}$ exo- and endonuclease activity is one of the most important biochemical features of MRE11 ${ }^{19}$. To determine whether the C-terminal truncation of MRE11 affected the enzymatic activity of MRE11, purified FLMRE11 (MRE11 wild-type), and TR-MRE11 (1-568 aa only) recombinant proteins (Fig. S4A, S4C) were identified and analysed by ESI-MS (Fig. S4B, S4D). When compared to FL-MRE11, the nuclease activity of TRMRE11 on partial duplex dsDNA was abolished, in a range of concentrations between 10 and $1000 \mathrm{nM}$ (1:10, 1:1, 10:1 molar ratio protein:dsDNA) (Fig. 3A, B). The nuclease products appeared to migrate approximately 34 nucleotides, consistent with the junction of the double stranded regions and what has been observed previously ${ }^{20}$. To determine whether defective DNA binding was responsible for the lack of nuclease activity, we performed a fluorescence polarization-based DNA binding assay $^{21}$ sing the same substrates as in the nuclease assay (Fig. 3C). The apparent affinity of TR-MRE11 was 7-fold lower than FL-MRE11 $(242.15 \mathrm{nM}$ and $34.56 \mathrm{nM}$, respectively). These data demonstrate that the $\mathrm{C}$-terminus contributed significantly to the DNA binding capacity and nuclease activity of MRE11.

The MRE11 dimer is the core scaffold, and the correct function of the MRN complex could be provided by the flexibility of its interaction with RAD50 and NBS1, which optimises MRN's allosteric organisation ${ }^{22-24}$. We investigated TR-MRE11's interaction with RAD50 and NBS1 by immunoprecipitation. Despite missing C-terminal motifs, TR-MRE11 efficiently interacted with RAD50, while NBS1 expression show a mild decrease over time (Fig. 3D, S6B). Altogether, these results suggest that TRMRE11 maintains an intact MRN complex but the nuclease activity of TR-MRE11 is abolished due to deficient DNA binding.

\section{YH2AX foci co-localised with FL-MRE11 but not with TR- MRE11 after IR}

We studied TR-MRE11 functions in bladder cancer cell lines of the two main molecular subtypes of muscleinvasive bladder cancer (RT112 for luminal and VMCUB1 for basal). Monoclonal cell lines expressing FL or TR-MRE11 were established in both MRE11 KD RT112 and MRE11 KD VM-CUB1 bladder cancer cells using lentivirus (Fig. 4A, S5A-B).

While the MRN complex binds to DNA double-strand breaks $(\mathrm{DSB})^{25}, \gamma \mathrm{H} 2 \mathrm{AX}$ is necessary for the recruitment of other factors to the sites of DNA damage ${ }^{26}$. MRE11 undergoes relocalisation in the nuclei during DNA replication in damaged cells and this relocalisation reflects the association of the complex with DNA damage ${ }^{27}$. We found that MRE11 colocalised with $\gamma \mathrm{H} 2 \mathrm{AX}$ at $24 \mathrm{~h}$ postIR in WT and FL-MRE11, but colocalization levels between MRE11 and $\gamma \mathrm{H} 2 \mathrm{AX}$ foci were decreased in TRMRE11 (Fig. 4B, C, S5C, D) in both cell lines.

In terms of $\gamma \mathrm{H} 2 \mathrm{AX}$ foci formation, using immunofluorescence microscopy, we investigated $\gamma \mathrm{H} 2 \mathrm{AX}$ and MRE11 foci at a 30 min timepoint after IR which is believed to be the peak time for formation of $\gamma \mathrm{H} 2 \mathrm{AX}$ foci. As the number of MRE11 foci was reduced by MRE11 KD 
A
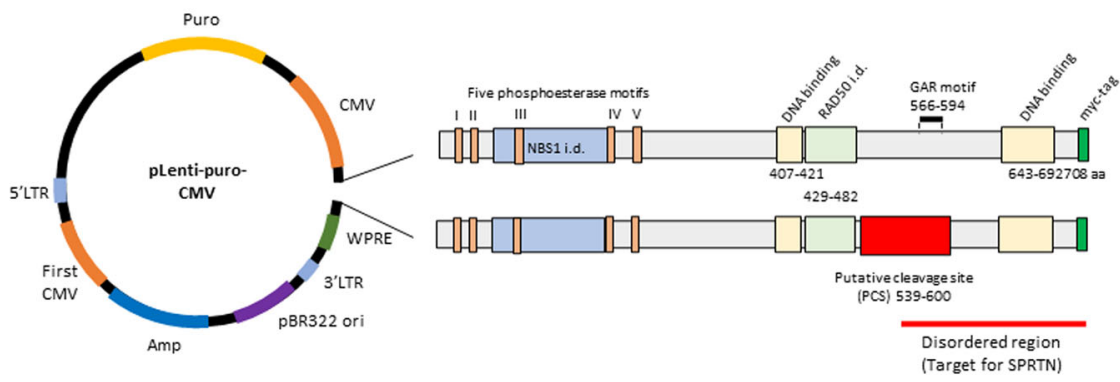

B

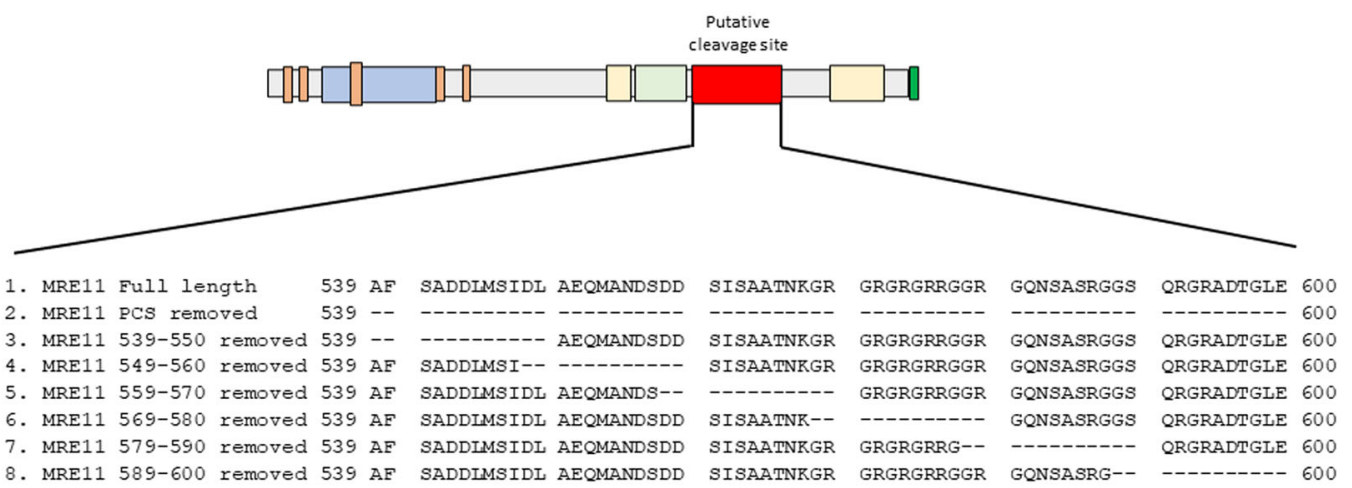

C

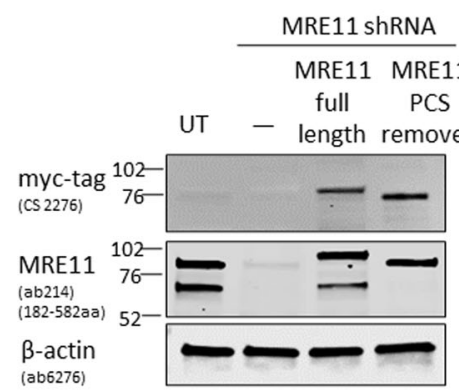

E

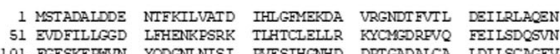

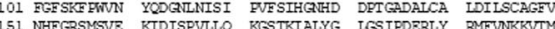
151

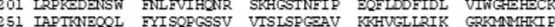
301 LHTVRQFHME DIVLANHPDI ANPDNPKNTO AIQSFCLEKI BEMLZNAERB 351 RLANSHQPER PLVRLRVDYS GGFEPFSULR FSQKTUDRVA NIFKDIIHFFR

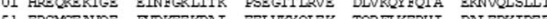
451 ERGMGEAVQE FVDKEEKDAI EELVKYOLER TORFLKERHI DALEDKIDEB 551 AEOMANDSDD STSAATNKGR GRGRGRRGGR GDNSASRGGS TRGRADTGLPE 601 TSTRSRNSKT AVSASRNASI TAAEKSTRCO PSRNMTTENY SEVIEYDESD 651 VEEDIFPTTS KTDDFWSSTS SSKMMSOSOV SKEVDFESSE DDODOPMMNT 701 SSLRRNRR

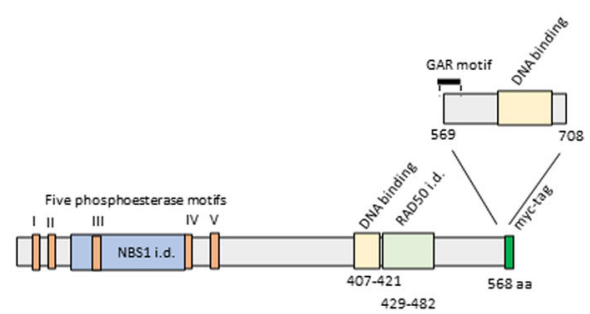

Fig. 2 (See legend on next page.)
D

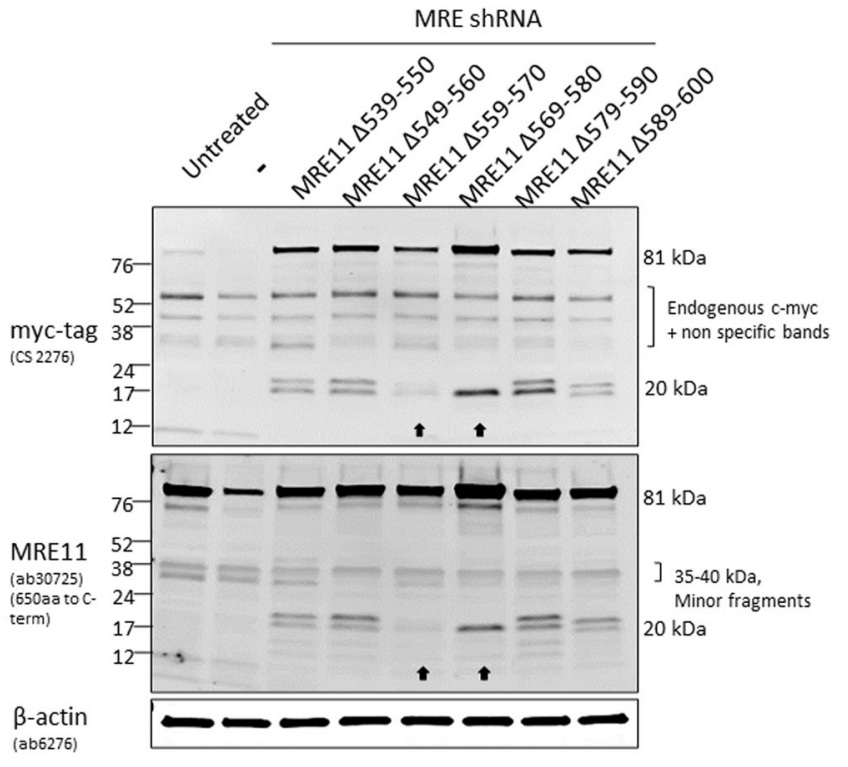


(see figure on previous page)

Fig. 2 The putative cleavage site in MRE11 lies within a 22 amino acid region, namely amino acids 559-580. A A map of the lentiviral vector including either intact MRE11 or MRE11 with the initial putative cleavage site (PCS) at amino acids 539-600 removed. The functional domains of MRE11 are indicated ${ }^{50,51}$. B Schematic representation of MRE11 with the various mutants, including complete deletion of the region (MRE11 PCS removed) and sequential deletions of 12 amino acids (MRE11 $\triangle 539-550, \triangle 549-560, \Delta 559-570, \triangle 569-580, \triangle 579-590$ and $\triangle 589-600$ ). C The MRE11 mutant lacking the initial putative cleavage site failed to generate truncated MRE11. D MRE11 mutants lacking either 559-570 or 569-580 aa did not generate the approximately 20 kDa size short form of cleaved MRE11 in RT112 cells, as seen using anti-myc-tag and anti-MRE11 ab 30725 antibodies. E pLenti-TR-MRE11 vector was designed by deleting 569-708 aa from FL-MRE11 (amino acids deleted shown in upper panel). Lower panel shows the truncation in diagrammatic form.

and this could be rescued by either FL-or TR-MRE11 (Fig S5F) from MRE11 KD, no significant change in the number of $\gamma \mathrm{H} 2 \mathrm{AX}$ foci was detected between FL- and TRMRE11 cell lines at $30 \mathrm{~min}$ post-IR (Fig S5G, H). However, the smaller numbers of $\gamma \mathrm{H} 2 \mathrm{AX}$ foci per MRE11 foci were observed in TR-MRE11 compared to FL-MRE11 in RT112 cell line (52 and $67 \gamma \mathrm{H} 2 \mathrm{AX}$ foci per 100 MRE11 foci, respectively), consistent with the result of VM-CUB1 cell line (51 and $59 \gamma \mathrm{H} 2 \mathrm{AX}$ foci per $100 \mathrm{MRE} 11$ foci, respectively) after IR, which indicates that the presence of the MRE11 truncation alters the cell's ability to increase the phosphorylation of $\mathrm{H} 2 \mathrm{AX}$ in response to ionising radiation (post-IR, 24 hr) (Figs. S5C, E, 4B, D). Altogether, this suggests that TR-MRE11 is less able to colocalise with $\gamma \mathrm{H} 2 \mathrm{AX}$, but that the truncation of MRE11 does not influence the number of $\gamma \mathrm{H} 2 \mathrm{AX}$ foci formed immediately after IR.

\section{TR-MRE11 cells have less efficient HR repair, and are more radiosensitive, with higher G2/M arrest than FL-MRE11 cells}

The pattern of protein expression of the MRN components was consistent after IR, indicating that the overall protein level of each component of the MRN complex was unchanged following ionising radiation (Fig. 5A, S6A). MRE11 KD and TR-MRE11 cells had lower levels of $\gamma \mathrm{H} 2 \mathrm{AX}$ protein expression in both non-irradiated and irradiated samples compared to WT and FL-MRE11 samples, consistent with immunofluorescence results (Fig. 4D, S5D). The effect of the various MRE11 variants on the cell cycle was evaluated by flow cytometric analysis. We observed that MRE11 KD cells induced increased G2/M cell cycle arrest (4.64-fold) after radiation ( $5 \mathrm{~Gy}, 16 \mathrm{~h}$ ), while control cells showed 3.65 times increase under the same conditions $(p<$ 0.0001) (Fig. 4F). This result is also consistent with the recent report $^{28}$ indicating that MRE11 deficit induces increased G2/ $\mathrm{M}$ arrest. We additionally identified that TR-MRE11 rescued cells showed more G2/M arrest (4.31-fold) than FL-MRE11 rescued cells (3.78-fold) after IR $(p<0.05)$ (Fig. 4E, F), suggesting that TR-MRE11 might have inefficient HR causing cell cycle arrest.

To determine the role of the MRE11 C-terminus in the HR repair pathway, we used the DR-GFP reporter system in U2OS cells. We found that the FL-MRE11 and TRMRE11 exhibited a significant increase in the restoration of the GFP+ cells over MRE11 KD cells (Fig. 5B). However, TR-MRE11 has been shown to significantly reduced HR repair efficiency when compared with the FL-MRE11, indicating the importance of C-terminal MRE11 in HR repair. Radiotherapy increase overall survival in the basal rather than the luminal cancer subtype ${ }^{29}$. Consistent with this, VM-CUB1 cells were more sensitive to radiation than RT112 cells in clonogenic assays (Fig. 5C, S6C). In both cell lines, the degree of radiation sensitivity in FLMRE11 was similar to that of wild-type, while the degree of radiation sensitivity in TR-MRE11 was similar to that of MRE11 KD which is more radiosensitive (Fig. 5C, D, S6D). To further evaluate whether the MRE11 deficient cells' sensitivity to IR is inducing apoptosis, we performed FACS analysis using FITC annexin V and PI (Fig. 5E, F). After both low (4 Gy) and high (8 Gy) doses of radiation, MRE11 KD showed significantly increased early apoptosis cells. TR-MRE11 cells had more early apoptosis cells than FL-MRE11 at the higher radiation dose, but not at the lower dose and not when compared to UT. No significant difference was observed in late apoptosis cells upon knockdown of MRE11 at either dose, although unexpectedly there was a difference between UT and transfected FL-and TR-MRE11 cells, both showing significantly less late apoptosis with this effect being more pronounced with the FL-MRE11. The differences in apoptosis do not fully explain the results in the survival assay, where a significant difference was observed between FL-and TRMRE11 cells even at lower doses. MRE11 does appear to play some role in early apoptosis but this role is not particularly dependent on the C-terminus.

Taken together, these results indicate that the C-terminus, including the glycine-arginine-rich (GAR) domain, is important for choosing the more efficient DNA damage repair pathway, G2/M progression, and cell survival after IR, but does not appear to play a significant role in apoptosis.

\section{Formation of TR-MRE11 is not caspase-dependent}

Previously, we showed that MRE11 cleavage occurs as a post-translational modification but that TR-MRE11 is not 
A

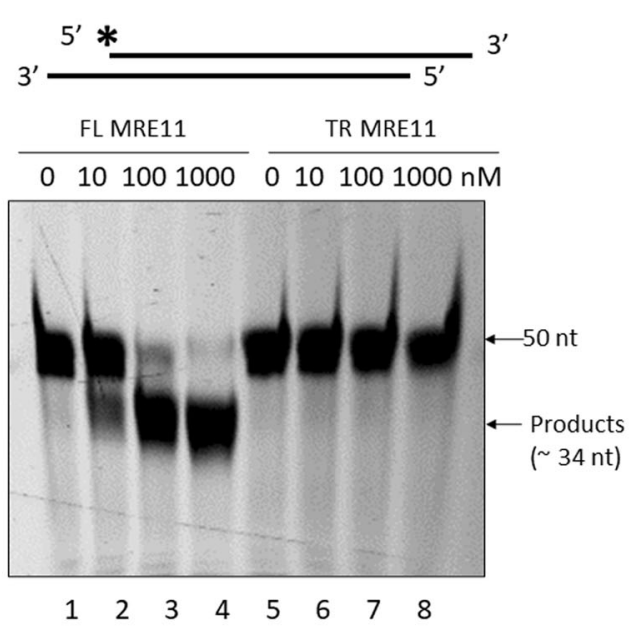

C

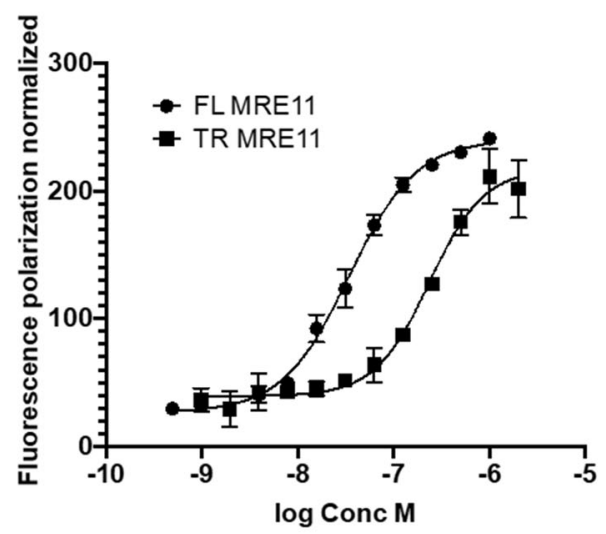

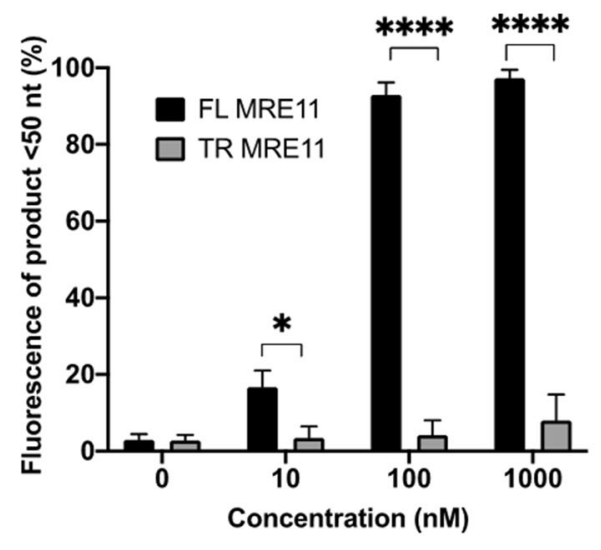

D

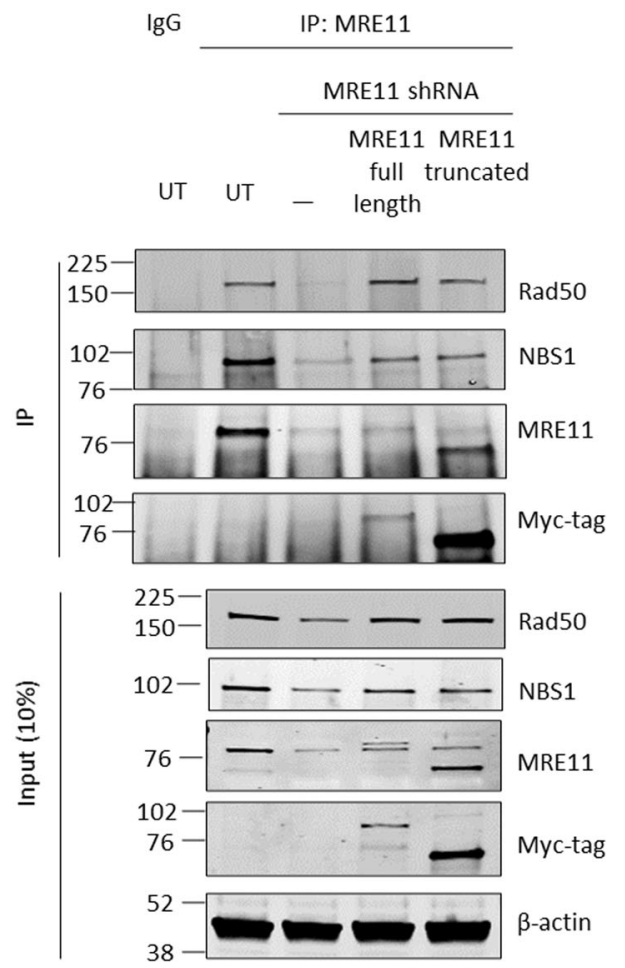

Fig. 3 TR-MRE11 lacks nuclease and DNA binding activities. A Nuclease assays of FL-MRE11 (lane 1, 2, 3, 4) and TR-MRE11 (lane 5, 6, 7, 8) on 3'overhang DNA substrates $(n=3)$. The FL-MRE11 shows clear dose-dependent nuclease activity which is absent in TR-MRE11. B Quantification of nuclease activity data in $(\mathbf{A})$. Error bars represent SEM $\left(P<0.0001\left(^{* * *}\right), P<0.05(*)\right)$. C Measurement of fluorescence polarisation $(n=1)$. The apparent dissociation constant for FL-MRE11 was $34.56 \mathrm{nM}$, whilst TR-MRE11 showed significantly reduced DNA binding (242.15 nM). D TR-MRE11 was still able to efficiently interact with RAD50 and NBS1, and this has been shown through immunoprecipitated MRE11 from VM-CUB1 protein lysates.

generated due to alternative splicing, because no alternative MRE11 transcripts were detected in amplified cDNA from MRE11 ${ }^{13}$. To determine how the levels of FL or TR-MRE11 expression are regulated, we first verified which cellular processes contribute to the cleavage of FLMRE11 to produce TR-MRE11. To investigate how TRMRE11 is produced, we exposed cells to various forms of damage, including overgrowth, starvation, blockage of protein synthesis, induction of hypoxia, blocking of DNA synthesis, HDAC inhibition, ionising radiation, and AKT inhibition, as it is known the MRE11-dependent pathway can contribute to localisation of pAKT-S473 ${ }^{30,31}$. Among these challenges only overgrowth significantly $(P<0.05)$ increased TR-MRE11 (Figs. S1, S7A). We found that TRMRE11 expression depends on cell density. There was a 2.3-fold increase in TR-MRE11 with higher cell numbers 


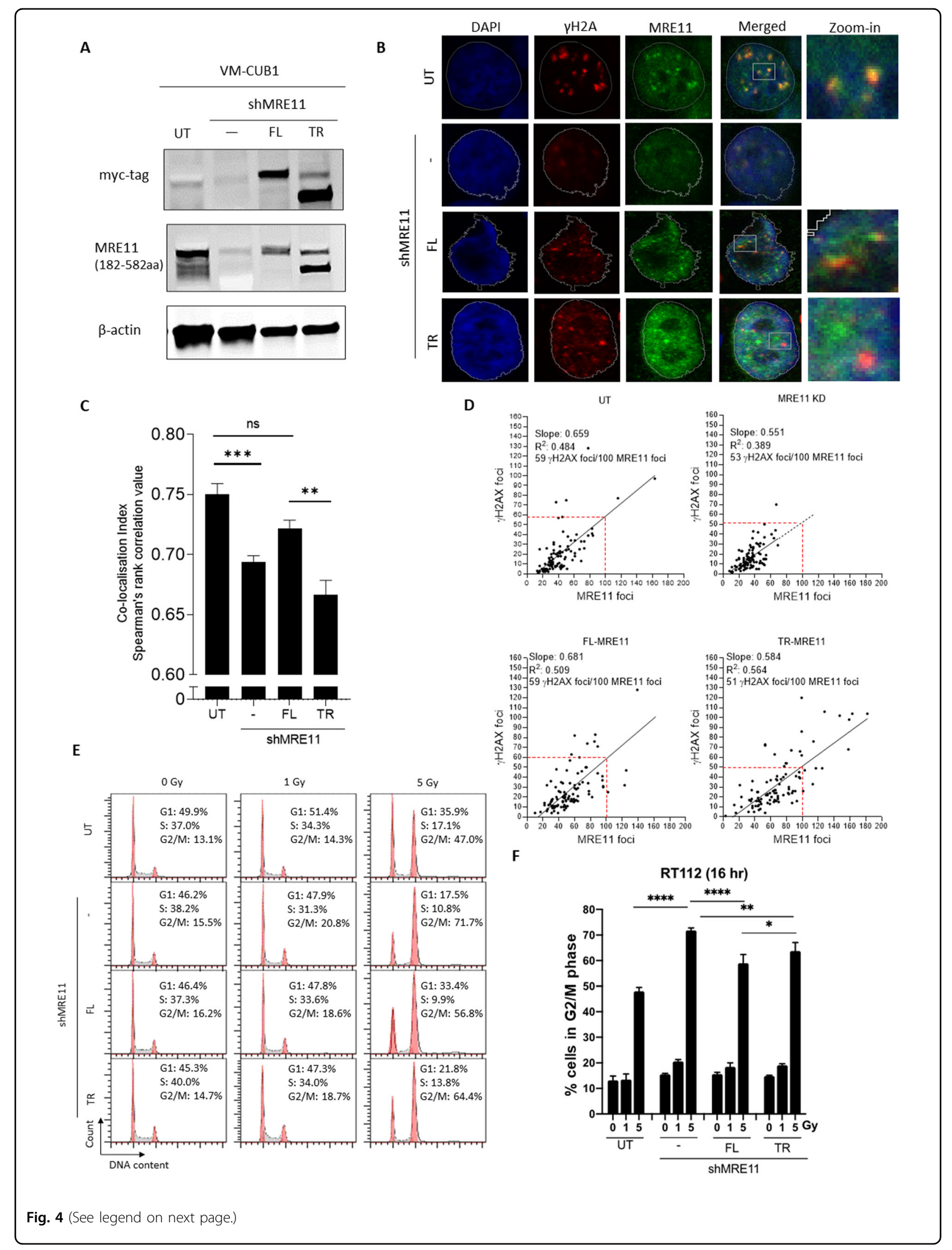


(see figure on previous page)

Fig. 4 TR-MRE11 co-localises less frequently than FL-MRE11 with $\mathrm{YH} 2 \mathrm{AX}$ after IR in VM-CUB1 cells. A Western blot of established cell lines from VM-CUB1. Endogenous MRE11 was knocked down and replaced with either exogenous FL or TR-MRE11, and named MRE11 knockdown (KD), FLMRE11, and TR-MRE11 cells, respectively. B Immunofluorescence microscopy of MRE11 and YH2AX foci showing co-localisation and some failure of co-localisation after IR (2 Gy, 24 hr post-IR). MRE11 foci were clearly knocked down in the shMRE11 sample and rescued in FL and TR. C TR-MRE11 colocalises with $\gamma \mathrm{H} 2 \mathrm{AX}$ less than FL-MRE11 does. Data are presented as means \pm SEM $\left(P<0.001(* * *), P<0.01\left({ }^{* *}\right)\right)$. D Correlation between MRE11 and $\mathrm{YH} 2 \mathrm{AX}$ foci numbers from (B). MRE11 deficient and TR-MRE11 cells showed non-significantly lower slopes for $\mathrm{YH} 2 \mathrm{AX}$ foci compared to FL-MRE11 and untreated cells. E Representative graphs for propidium iodide cell cycle. F Cell cycle distribution of RT112 UT, KD, FL-MRE11, and TR-MRE11 cells was quantitatively analysed using flow cytometry ${ }^{* * *}<0.0001,{ }^{* *}<0.01,{ }^{*} P<0.05$; one-way ANOVA, $n=3$, mean + SEM).

(Fig. S1A-C). TR-MRE11 also increased in a cell densitydependent manner (Fig. S1D, E). In order to elucidate the mechanism, we first focused on the seven aspartic acids which might be a potential target for caspases. We tested a range of concentrations of the pan-caspase inhibitor ZVAD-FMK (carbobenzoxy-valyl-alanyl-aspartyl-[Omethyl]-fluoromethylketone) in DMSO. MRE11 cleavage was not affected by inhibition with a range of doses of ZVAD-FMK (Fig. S7B). We next tested individual caspase inhibitors 1, 2, 3, 4, 5, 6, 8, 9, 10 and 13, and again could not detect any significant alteration in TR-MRE11 expression levels (Fig. S7C). This suggests that caspases do not appear to be the proteases responsible for cleaving MRE11.

\section{MRE11 is a substrate of the SPRTN protease}

We then chose to study the DNA-dependent mammalian metalloprotease, SPRTN, which is essential for DNAprotein crosslink (DPC) repair and DNA replication in vertebrate cells ${ }^{32}$. SPRTN is a DNA-dependent, but amino-acid sequence non-specific, protease. Its known substrates (e.g. histones) are cleaved in disordered protein regions in the vicinity of arginine, lysine and serine residues $^{18}$. Thus SPRTN was a promising candidate responsible for the MRE11 cleavage, as the C-terminus of MRE11 is predicted to be intrinsically highly disordered (Fig. S3). Furthermore, the MRE11 GAR domain (Fig. 2A), located between $566-594 \mathrm{aa}^{33}$, contains nine positivelycharged arginines out of its 29 amino acids and is also disordered. This region could therefore be a possible candidate substrate for SPRTN.

To investigate whether post-translational MRE11 cleavage is mediated by SPRTN, endogenous SPRTN was depleted using siRNA targeting the $3^{\prime}$ UTR of SPRTN transcripts. Knockdown of SPRTN resulted in a dosedependent reduction in TR-MRE11 compared with scrambled siRNA-treated samples (Fig. 6A, B) although SPRTN knockdown did not influence to the protein expression level of RAD50 and NBS1, the MRE11's interacting partners (Fig. S8C). There was a significant correlation between TR-MRE11 and SPRTN levels (Fig. 6C). Unexpectedly, SPRTN expression decreased upon treatment with HDACi (Fig S8A), and no effect was observed upon overgrowth (Fig S8B). We also observed large decrease in NBS1 and RAD50 upon treatment with panobinostat, suggesting that this affects levels of multiple cellular proteins. We overexpressed SPRTN protein to investigate whether this influenced survival following ionising radiation. Interestingly, overexpressed SPRTN increased sensitivity to radiation therapy, and this may be explained by the effect of SPRTN on MRE11 (Figs. 6D-F). Moreover, the increased IR sensitivity of SPRTN in MRE11 KD cells indicates that possible additional targets of SPRTN may be involved. Together, these results indicate that SPRTN is a factor mediating cleavage of MRE11 and overexpressed SPRTN increases radiosensitivity.

\section{SPRTN protease cleaves MRE11 in vitro}

To further investigate the role of SPRTN protease in MRE11 cleavage, we performed an in vitro cleavage assay using recombinant proteins. Recombinant MRE11 protein was cleaved upon incubation with purified SPRTN recombinant protein and $100 \mathrm{bp}$ dsDNA in vitro, but not with enzymatically-dead SPRTN variant (SPRTN E112A) (Fig. 6G). Incubation of MRE11 with SPRTN yielded a main N-terminal cleavage product of approximately $\sim 65 \mathrm{kDa}$ (arrow indicated) and others $<17 \mathrm{kDa}$ (bracket indicated), which were absent when SPRTN-E112A was used instead. In addition, the $\mathrm{C}$-terminal binding antibody detected a small fragment $(<17 \mathrm{kDa})$ specifically produced by SPRTN activity, reminiscent of the two small bands from the cell lysate at $\sim 12 \mathrm{kDa}$ (Fig. 2D). This demonstrates that the cleavage product generated by SPRTN is missing the C-terminal of MRE11, similar to the TRMRE11 form in some bladder cancer cells (Fig. 1A, B). These results suggest that TR-MRE11 could be a SPRTN cleavage product. To investigate whether overexpressed SPRTN and MRE11 form a stable interaction, we performed immunoprecipitation using flag-SPRTN transfection. Intact SPRTN complex was pulled down with its interacting partners, and this was shown via anti-p97, one of the strongest interacting partners to SPRTN (Fig. $6 \mathrm{H})$. We did not detect a direct interaction between SPRTN and FL-MRE11. Although the presence of a stable interaction is not necessary for the protease cleavage which can happen in a transient manner, we did 
A

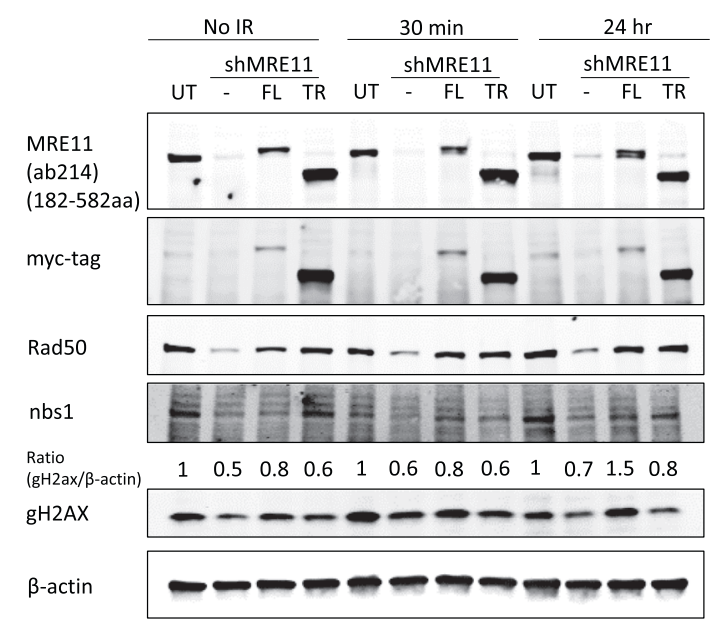

C

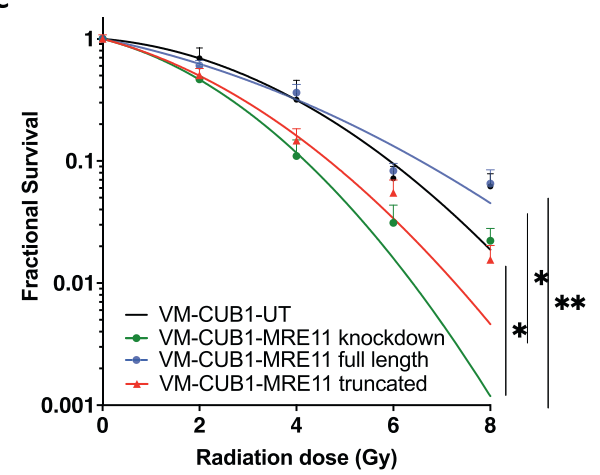

E

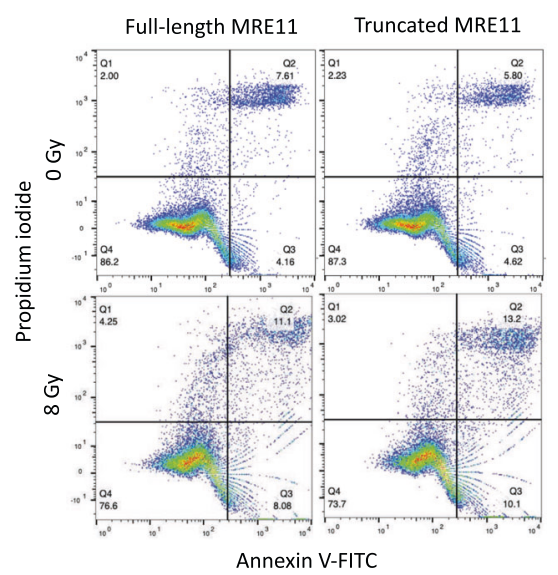

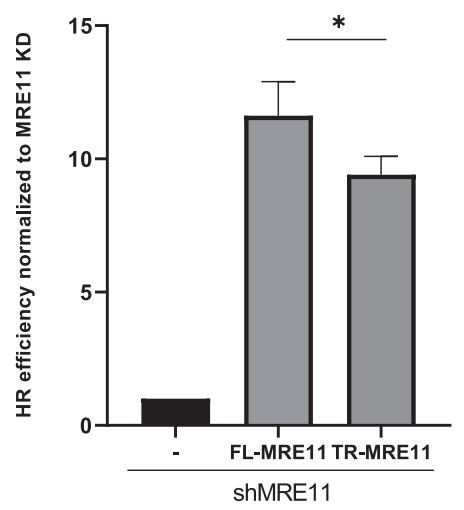

D
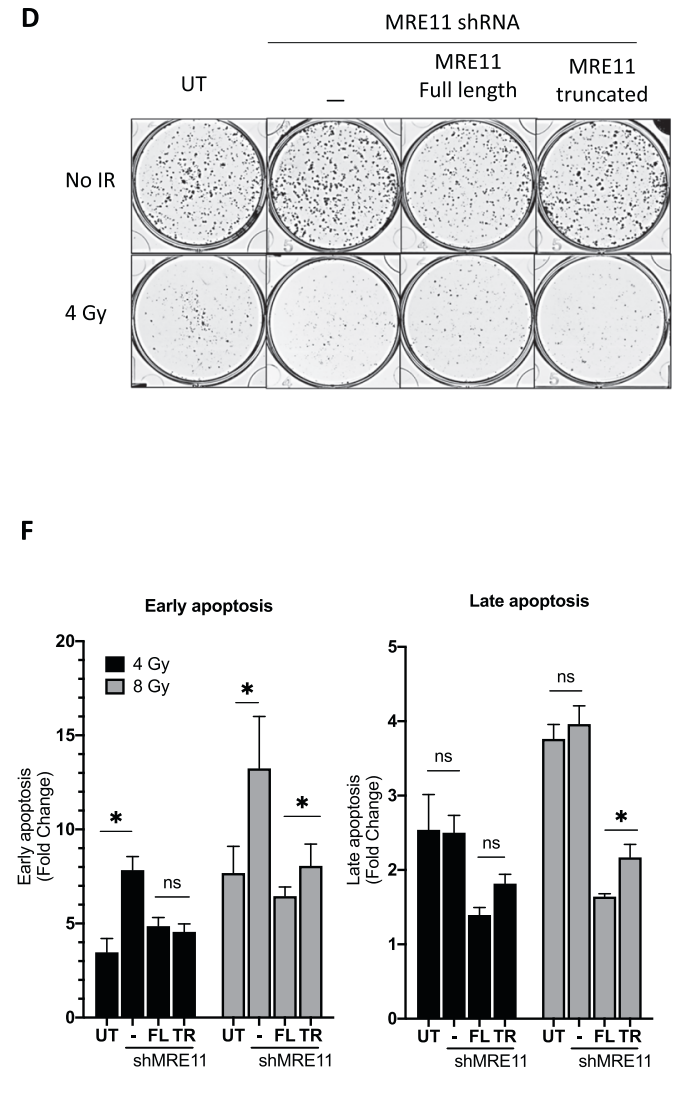

Fig. 5 Cells expressing TR-MRE11 are more radiosensitive and deficiency in HR repair than those expressing FL-MRE11. A The protein expression levels of the MRN complex subunits were unchanged after IR (2 Gy). MRE11 KD and TR-MRE11 showed less increased level of $\gamma H 2 A X$ compared to WT after IR. B GFP based reporter assay showing the efficiency of HR repair pathway under FL-MRE11 or TR-MRE11 rescued condition as indicated. Graph represents the quantifications from three independent experiments ( ${ }^{*} P<0.05$; one-way ANOVA, $n=3$, mean + SEM). C Clonogenic survival rates of TRMRE11 and KD cells were lower than for FL-MRE11 and untreated cells. The response to ionising irradiation is represented by the linear-quadratic model. KD cells had significantly lower survival rate than UT cells $(P<0.05)$. TR-MRE11 cells had significantly lower survival rate than FL-MRE11 $(P<0.05)$ at 4 Gy. D The representative image of (C). E Flow cytometric analysis results of various RT112 cells after $8 \mathrm{~Gy}$ IR (48 h). F A statistical plot of annexin V-FITC/PI staining for (E) is shown for both early and late apoptosis after 4 and $8 \mathrm{~Gy} I \mathrm{IR}(48 \mathrm{~h})$. The results are expressed as the means $\pm \mathrm{SD}\left({ }^{* * * *}<0.0001,{ }^{* *}<0.01,{ }^{*} P<0.05\right)$. 
detect some low molecular weight bands with the monoclonal anti-MRE11 targeting $182-582$ aa epitope (Fig. 6H), which may correspond to MRE11 cleavage products that interact with SPRTN. Further studies would be required in order to investigate this possibility more thoroughly.

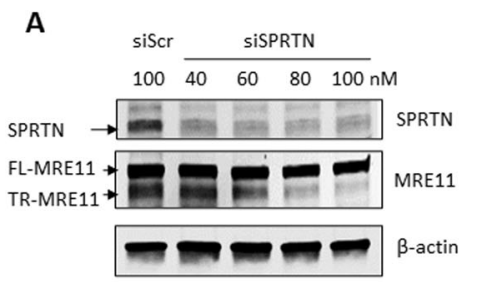

D

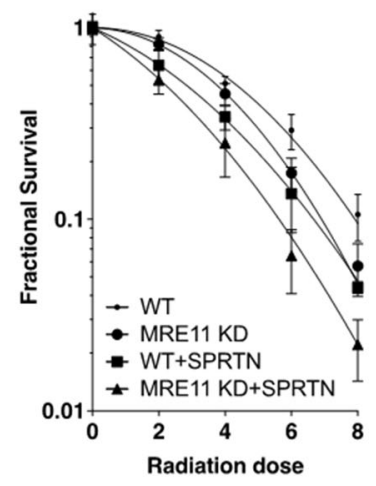

B

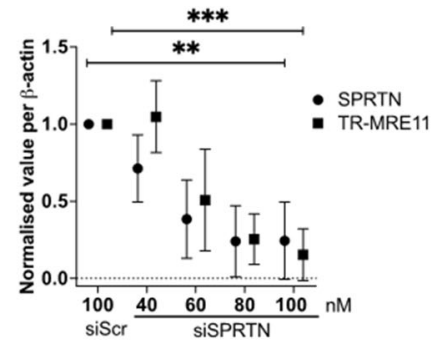

E

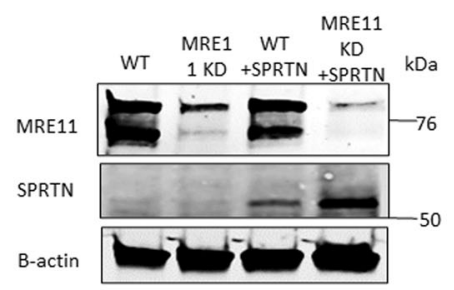

C

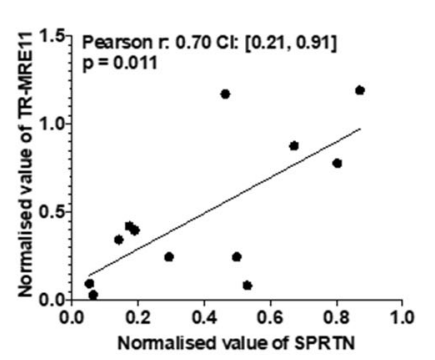

$\mathbf{F}$

WT

MRE11 KD

WT+SPRTN

MRE11 KD +SPRTN

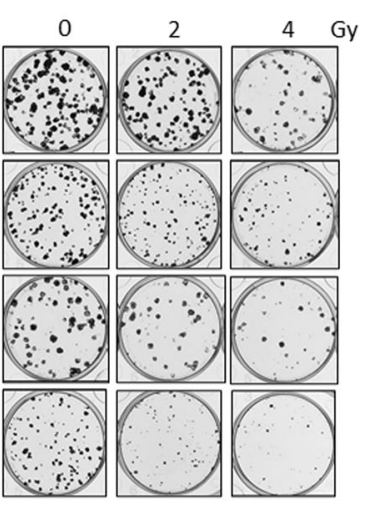

G

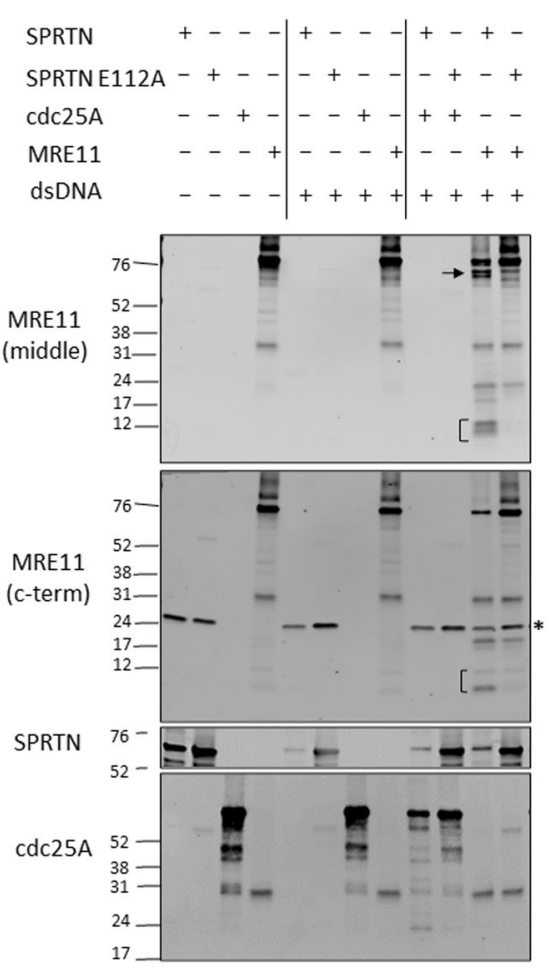

H

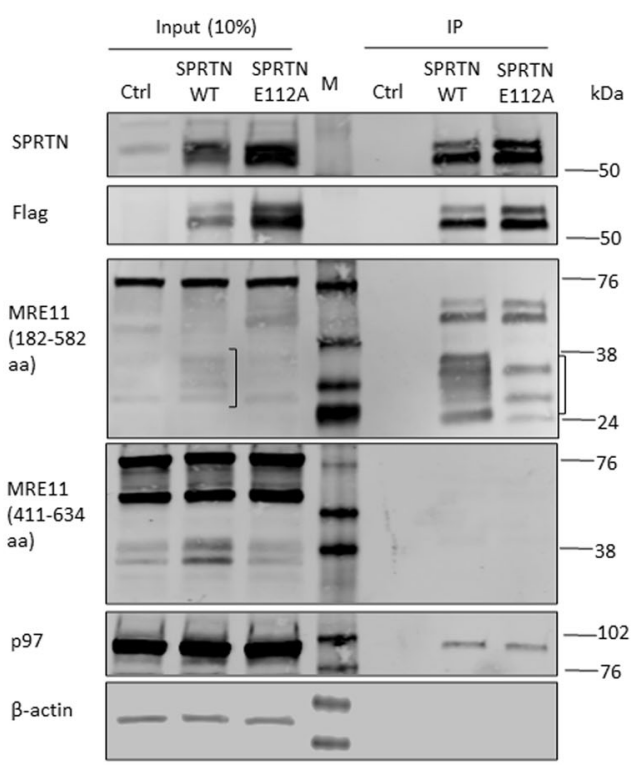

Fig. 6 (See legend on next page.) 
(see figure on previous page)

Fig. 6 MRE11 is cleaved in cells and in vitro by the SPRTN metalloprotease and SPRTN overexpression increases radiosensitivity. A siRNAtargeting SPRTN in RT112 cells regulates the levels of TR-MRE11. siRNA was used indicated concentrations 40, 60, 80 and $100 \mathrm{nM}$ for $72 \mathrm{~h}$, with scrambled siRNA as a positive control. Pictures are representative from 3 replicates with similar results. B Quantification of TR-MRE11 and SPRTN knockdown level from (A). C A significant correlation was found between TR-MRE11 and SPRTN protein expression levels $(p=0.011)$. D Clonogenic survival rates of SPRTN overexpressed cells were lower after IR than for WT cells in RT112. The response to ionising irradiation is represented by the linear-quadratic model. MRE11 KD+SPRTN cells had significantly lower survival rate than WT+SPRTN cells $(P<0.05)$. WT+SPRTN cells had significantly lower survival rate than WT $(P<0.05)$. E SPRTN overexpression in WT and MRE11 KD cells was confirmed by Western blotting. $\mathbf{F}$ The representative images of (D). G In vitro cleavage assay using recombinant proteins. TR-MRE11, indicated with arrow, was released only in the presence of active SPRTN. A blot for anti-MRE11 (C-terminus) antibody shows nonspecific binding to SPRTN protein, marked with asterisk. Cdc25A was used as a positive control for SPRTN activity (the size of the cleaved products is $\sim 5 \mathrm{kDa}$ smaller than the products in Fig. 2D, as this recombinant protein does not include tag part in C-terminus). $\mathbf{H}$ Immunoprecipitation of 293T cell lysate using SPRTN-WT and SPRTN-E112A. p97, the strong interacting partner for SPRTN, was used as a positive control for SPRTN interacting protein.

\section{Discussion}

MRE11 has been intensively studied because of its importance in genome stability, DNA damage repair, and its nuclease activity. However, the reason why high MRE11 protein expression, by immunohistochemistry using an antibody with an epitope spanning amino acids 182-582, is associated with better survival rate in bladder cancer patients after radiotherapy ${ }^{34,35}$ has not yet been explained. We hypothesised that the truncated form of MRE11 may explain the negative correlation between the level of MRE11 expression and radiotherapy outcome, in terms of DNA repair.

Human MRE11 bears a glycine-arginine-rich (GAR) motif that is conserved among multicellular eukaryotic species $^{36}$. They are essential for not only the regulation of MRE11 DNA binding and nuclease activity, but also MRE11 and RAD51 focus formation on a unique DSB in vivo ${ }^{33}$. Posttranslational modifications of MRE11, such as methylated arginine GAR motif and DSB processing, as well as ATR/CHK1 checkpoint signalling, appears to influence DNA damage repair and has been demonstrated previously $^{37}$. According to Dery et al. 2008, MRE11$\triangle$ GAR on dsDNA displayed only weak residual exonuclease activity compared to that of methylated MRE11WT. Additionally, we have shown in this current report that MRE11 recombinant protein without methylation would also have lack of nuclease activity after cleavage. Mutations in MRE11 are responsible for the human radiation sensitivity disorder Ataxia-telangiectasia-like disorder (ATLD), which is characterised by defective checkpoint responses and high levels of chromosomal abnormalities $^{20}$. The authors found that in ATLD 1/2 where MRE11 contained a stop codon instead of R633, $\sim 50 \%$ residual nuclease activity remained. Both MRE11$\triangle$ GAR and ATLD 1/2 share a number of key features, such as having weak nuclease activity through loss of part of MRE11. Furthermore, this paper offers the evidence that the post-translationally induced TR-MRE11 forms (G569stop) lost its nuclease activity due to lack of DNA binding affinity (Fig. 3) reminiscent of MRE11- $\triangle$ GAR and
ATLD1/2. Despite this, TR-MRE11 interacted efficiently with RAD50 and NBS1 (Fig. 3D, S6B). As truncated MRE11 physiologically interacts with its MRN partners but is completely defective in nuclease activity, it is likely that the complex containing TR-MRE11 may have reduced DNA binding and nuclease activity, but this remains to be tested. Overall, a C-terminally truncated form of MRE11 is capable of maintaining the interactions between the MRN complex units while limiting its enzyme activity.

MRE11 participates in both NHEJ and HR DNA repair pathways $^{7,38}$. Elimination of resection mechanisms (MRE11 $\Delta$ exo1 $\Delta \operatorname{sgs} 1 \Delta$ triple mutants) prevents HR and causes lethality in budding yeast ${ }^{39}$. Thus, we investigated whether FL-MRE11 and TR-MRE11 cells displayed similar ratios of HR repair pathway usage. In the HR assay used in this study, FL-MRE11 cells promoted efficient HR repair pathway compared to TR-MRE11 cells (Fig. 5B). Furthermore, $\mathrm{Xu}$ et al. showed that MRE11 knockdown caused radiosensitivity in an adenocarcinoma cell line ${ }^{40}$, which resembles our finding in this paper. C-terminally truncated MRE11 also caused radiosensitivity as MRE11 knockdown did but showed a lower degree of slope (Fig. $5 \mathrm{C}, \mathrm{D}, \mathrm{S} 6 \mathrm{C}, \mathrm{D})$. The cell proliferation test using the MTT assay did not reveal any significant results after various doses of IR (Fig. S6E), indicating that MRE11 deficiency mediated cell survival and cell cycle progression but did not show dramatically altered cell proliferation rates.

Phosphorylated H2AX at ser 139 has been found at the sites of DSB in chromosomal DNA and $\gamma \mathrm{H} 2 \mathrm{AX}$ is a key component of various signalling pathways related to DNA $\mathrm{DSB}^{41,42} \cdot \gamma \mathrm{H} 2 \mathrm{AX}$ focus formation is considered to be a sensitive signal for DNA DSB and necessary for rapid DDR signal amplification ${ }^{43,44}$. In addition, $\gamma \mathrm{H} 2 \mathrm{AX}$ directly binds NBS1 which then allows the recruitment of other DDR proteins, including the MRN complex at DNA DSB sites, and these foci co-localise with DNA repair and checkpoint proteins ${ }^{26,45,46} \cdot \gamma \mathrm{H} 2 \mathrm{AX}$ recruits the MRE11 complex to damaged DNA over time ${ }^{26,46}$. The level of colocalisation with TR-MRE11 and $\gamma \mathrm{H} 2 \mathrm{AX}$ foci were 
significantly lower than that of FL-MRE11, indicating that the C-terminus of MRE11 is important for recognition of MRE11 recruitment by $\gamma \mathrm{H} 2 \mathrm{AX}$ (Fig. 4B, C, S5C, D).

Our findings also address another key question of what results in accumulation of TR-MRE11. The only factor that appeared to have an effect on TR-MRE11 levels was overgrowth or high cell density, which is known to affect multiple cellular processes (Fig. S7). Some possible caspase cleavage motifs including 560 (DSDD*SISA) aa in the PCS of MRE11 were identified by Cascleave ${ }^{47}$. However, we found no correlation (Fig. S7B, C) but found that SPRTN metalloprotease was involved. MRE11 cleavage was dependent on SPRTN and the level of TR-MRE11 was dependent on SPRTN expression (Fig. 6). These data indicates that SPRTN can induce MRE11 truncated forms in the cell. Further experiments are necessary to determine which of the domains in SPRTN is crucial for MRE11 cleavage, either through rescuing SPRTN-wt or SPRTN-mutated in SPRTN KD cells. Furthermore, the physiological importance of MRE11 cleavage in SPRTNmediated DPC degradation should also be explored. The Cancer Genome Atlas (TCGA) data reveals that higher SPRTN levels were associated with decreased patient survival rates, and it was elevated in some of cancer types (Fig S8E, G). Furthermore, SPRTN levels were not significantly correlated with MRE11 levels and were independent of cancer stage (Fig S8D, F).

Previously, we found that bladder cancer patients with high MRE11 expression paradoxically have shown higher survival rates after radiation therapy, despite MRE11 being involved in repair of DNA DSB caused by ionising radiation ${ }^{34}$. This finding was validated by Laurberg et al. in an independent cohort. These findings might now be explained due to the presence of the truncated form of MRE11.

\section{Acknowledgements}

Mass spectrometry analysis was performed in the MS laboratory at the Target discovery institute-NDM (Oxford) led by Benedikt M. Kessler. We thank Drs. Eva McGrowder and Blaz Groselj for processing of primary bladder tumour samples to produce cell-free extracts.

\section{Funding}

This work was funded by CRUK Programme Grant C5255/A23755.

\section{Author details \\ 'MRC Oxford Institute for Radiation Oncology, Department of Oncology, University of Oxford, Oxford OX3 7DQ, UK. ${ }^{2}$ Centre for Medicines Discovery, University of Oxford, Oxford, UK. ${ }^{3}$ Target Discovery Institute, Nuffield Department of Medicine, University of Oxford, Oxford, UK}

\section{Author contributions}

J. Na and A. Kiltie performed study concept and design; J. Na and A. Kiltie performed development of methodology and writing the paper; J. $\mathrm{Na}$, J. Newman, J. Syed, I. Vendrell, I. Torrecilla, K. Ramadan, R. Fischer and A. Kiltie performed review and revision of the paper; J. Na, J. Newman, C.K. Then, J. Syed, I. Vendrell, S. Ellermann and I. Torrecialla provided acquisition, analysis and interpretation of data, and statistical analysis; A. Kiltie supervised this study. All authors read and approved the final paper.

\section{Data availability}

The LC-MS/MS proteomics data have been deposited to the ProteomeXchange Consortium via the PRIDE ${ }^{48}$ partner repository with the dataset identifier PXD017964 and 10.6019/PXD017964.

\section{Conflict of interest}

The authors declare that they have no conflict of interest.

\section{Ethics statement}

Ethical approval for the use of patient samples was obtained from South Central Oxford Research Ethics Committee C09/H0606/5.

\section{Publisher's note}

Springer Nature remains neutral with regard to jurisdictional claims in published maps and institutional affiliations.

Supplementary information The online version contains supplementary material available at https://doi.org/10.1038/s41419-021-03437-w.

Received: 5 June 2020 Revised: 7 January 2021 Accepted: 11 January 2021 Published online: 08 February 2021

\section{References}

1. Zha, S., Boboila, C. \& Alt, F. W. Mre1 1: roles in DNA repair beyond homologous recombination. Nat. Struct. Mol. Biol. 16, 798-800 (2009).

2. Paull, T. T. 20 Years of Mre11 biology: no end in sight. Mol. Cell. 71, 419-427 (2018).

3. Lamarche, B. J., Orazio, N. I. \& Weitzman, M. D. The MRN complex in doublestrand break repair and telomere maintenance. FEBS Lett. 584, 3682-3695 (2010).

4. Stracker, T. H. \& Petrini, J. H. The MRE11 complex: starting from the ends. Nat. Rev. Mol. Cell Biol. 12, 90-103 (2011).

5. Williams, G. J. et al. ABC ATPase signature helices in Rad50 link nucleotide state to Mre11 interface for DNA repair. Nat. Struct. Mol. Biol. 18, 423-431 (2011).

6. Lisby, M., Barlow, J. H., Burgess, R. C. \& Rothstein, R. Choreography of the DNA damage response: spatiotemporal relationships among checkpoint and repair proteins. Cell 118, 699-713 (2004).

7. Shibata, A. et al. DNA double-strand break repair pathway choice is directed by distinct MRE11 nuclease activities. Mol. Cell. 53, 7-18 (2014).

8. D'Amours, D. \& Jackson, S. P. The Mre11 complex: at the crossroads of dna repair and checkpoint signalling. Nat. Rev. Mol. Cell Biol. 3, 317-327 (2002).

9. Buis, J. et al. Mre11 nuclease activity has essential roles in DNA repair and genomic stability distinct from ATM activation. Cell 135, 85-96 (2008).

10. Luo, G. et al. Disruption of mRad50 causes embryonic stem cell lethality, abnormal embryonic development, and sensitivity to ionizing radiation. Proc. Natl Acad. Sci. USA 96, 7376-7381 (1999).

11. Zhu, J., Petersen, S., Tessarollo, L. \& Nussenzweig, A. Targeted disruption of the Nijmegen breakage syndrome gene NBS1 leads to early embryonic lethality in mice. Curr. Biol. 11, 105-109 (2001).

12. Stewart, G. S. et al. The DNA double-strand break repair gene hMRE11 is mutated in individuals with an ataxia-telangiectasia-like disorder. Cell 99, 577-587 (1999).

13. Nicholson, J. et al. E3 Ligase CIAP2 Mediates Downregulation of MRE11 and Radiosensitization in Response to HDAC Inhibition in Bladder Cancer. Cancer Res. 77, 3027-3039 (2017).

14. Link, A. J. \& Labaer, J. In-gel trypsin digest of gel-fractionated proteins. Cold Spring Harb. Protoc. 2009, pdb prot5110 (2009).

15. Davis, S. et al. Expanding Proteome Coverage with CHarge Ordered Parallel Ion aNalysis (CHOPIN) Combined with Broad Specificity Proteolysis. J. Proteome Res. 16, 1288-1299 (2017).

16. Bennardo, N., Cheng, A., Huang, N. \& Stark, J. M. Alternative-NHEJ is a mechanistically distinct pathway of mammalian chromosome break repair. PLoS Genet. 4, e1000110 (2008).

17. Halder, S. et al. SPRTN protease and checkpoint kinase 1 cross-activation loop safeguards DNA replication. Nat. Commun. 10, 3142 (2019).

18. Vaz, B. et al. Metalloprotease SPRTN/DVC1 orchestrates replication-coupled DNA-protein crosslink repair. Mol. Cell. 64, 704-719 (2016). 
19. Paull, T. T. \& Gellert, M. The $3^{\prime}$ to $5^{\prime}$ exonuclease activity of Mre 11 facilitates repair of DNA double-strand breaks. Mol. Cell. 1, 969-979 (1998).

20. Lee, J. H. et al. Regulation of Mre11/Rad50 by Nbs1: effects on nucleotidedependent DNA binding and association with ataxia-telangiectasia-like disorder mutant complexes. J. Biol. Chem. 278, 45171-45181 (2003).

21. Moerke, N. J. Fluorescence polarization (FP) assays for monitoring peptideprotein or nucleic acid-protein binding. Curr. Protoc. Chem. Biol. 1, 1-15 (2009).

22. Moiani, D. et al. Targeting allostery with avatars to design inhibitors assessed by cell activity: dissecting MRE11 endo- and exonuclease activities. Methods Enzymol. 601, 205-241 (2018).

23. Crown, K. N. et al. A mutation in the FHA domain of Coprinus cinereus Nbs1 Leads to Spo11-independent meiotic recombination and chromosome segregation. G3 (Bethesda). 3, 1927-1943 (2013).

24. Rojowska, A. et al. Structure of the Rad50 DNA double-strand break repair protein in complex with DNA. EMBO J. 33, 2847-2859 (2014),

25. Furuta, T. et al. Phosphorylation of histone H2AX and activation of Mre11, Rad50, and Nbs1 in response to replication-dependent DNA double-strand breaks induced by mammalian DNA topoisomerase I cleavage complexes. J. Biol. Chem. 278, 20303-20312 (2003).

26. Paull, T. T. et al. A critical role for histone $H 2 A X$ in recruitment of repair factors to nuclear foci after DNA damage. Curr. Biol. 10, 886-895 (2000).

27. Mirzoeva, O. K. \& Petrini, J. H. DNA damage-dependent nuclear dynamics of the Mre11 complex. Mol. Cell Biol. 21, 281-288 (2001).

28. Federico, M. B. et al. Unscheduled MRE11 activity triggers cell death but not chromosome instability in polymerase eta-depleted cells subjected to UV irradiation. Oncogene 39, 3952-3964 (2020).

29. Mao, J. H., Diest, P. J. V., Perez-Losada, J. \& Snijders, A. M. Revisiting the impact of age and molecular subtype on overall survival after radiotherapy in breast cancer patients. Sci. Rep. 7, 12587 (2017).

30. Fraser, M. et al. MRE11 promotes AKT phosphorylation in direct response to DNA double-strand breaks. Cell Cycle 10, 2218-2232 (2011).

31. Piscitello, D. et al. AKT overactivation can suppress DNA repair via p70S6 kinase-dependent downregulation of MRE11. Oncogene 37, 427-438 (2018).

32. Halder S. et al. SPRTN Protease and checkpoint kinase 1 cross-activation loop safeguards DNA replication. Nat. Commun. 10, 3142 (2019).

33. Dery, $U$. et al. A glycine-arginine domain in control of the human MRE11 DNA repair protein. Mol. Cell Biol. 28, 3058-3069 (2008).

34. Choudhury, A. et al. MRE11 expression is predictive of cause-specific survival following radical radiotherapy for muscle-invasive bladder cancer. Cancer Res. 70, 7017-7026 (2010).
35. Laurberg, J. R. et al. Expression of TIP60 (tat-interactive protein) and MRE11 (meiotic recombination 11 homolog) predict treatment-specific outcome of localised invasive bladder cancer. BJU Int. 110, E1228-E1236 (2012).

36. Boisvert, F. M., Dery, U., Masson, J. Y. \& Richard, S. Arginine methylation of MRE11 by PRMT1 is required for DNA damage checkpoint control. Genes Dev. 19, 671-676 (2005).

37. Yu, Z. et al. The MRE11 GAR motif regulates DNA double-strand break processing and ATR activation. Cell Res. 22, 305-320 (2012).

38. Thompson, L. H. \& Schild, D. Homologous recombinational repair of DNA ensures mammalian chromosome stability. Mutat. Res. 477, 131-153 (2001).

39. Mimitou, E. P. \& Symington, L. S. Sae2 Exo1 and Sgs1 collaborate in DNA double-strand break processing. Nature 455, 770-774 (2008).

40. $\mathrm{Xu}, \mathrm{M}$. et al. Transfection of human tumour cells with Mre11 siRNA and the increase in radiation sensitivity and the reduction in heat-induced radiosensitization. Int J. Hyperth. 20, 157-162 (2004).

41. Dickey, J. S. et al. H2AX: functional roles and potential applications. Chromosoma 118, 683-692 (2009).

42. Bonner, W. M. et al. GammaH2AX and cancer. Nat. Rev. Cancer 8, 957-967 (2008).

43. Modesti, M. \& Kanaar, R. DNA repair: spot(light)s on chromatin. Curr. Biol. 11, R229-R232 (2001).

44. Stucki, M. \& Jackson, S. P. MDC1/NFBD1: a key regulator of the DNA damage response in higher eukaryotes. DNA Repair (Amst.). 3, 953-957 (2004).

45. Mailand, N. et al. RNF8 ubiquitylates histones at DNA double-strand breaks and promotes assembly of repair proteins. Cell 131, 887-900 (2007).

46. Celeste, A. et al. Genomic instability in mice lacking histone H2AX. Science $\mathbf{2 9 6}$ 922-927 (2002).

47. Song, J. et al. Cascleave: towards more accurate prediction of caspase substrate cleavage sites. Bioinformatics 26, 752-760 (2010).

48. Perez-Riverol, Y. et al. The PRIDE database and related tools and resources in 2019: improving support for quantification data. Nucleic Acids Res. 47, D442-D450 (2019).

49. Kerr, M. et al. Deoxycytidine kinase expression underpins response to gemcitabine in bladder cancer. Clin. Cancer Res. 20, 5435-5445 (2014).

50. Damiola, F. et al. Rare key functional domain missense substitutions in MRE11A, RAD50, and NBN contribute to breast cancer susceptibility: results from a Breast Cancer Family Registry case-control mutation-screening study. Breast Cancer Res. 16, R58 (2014).

51. Williams, G. J., Lees-Miller, S. P. \& Tainer, J. A. Mre11-Rad50-Nbs1 conformations and the control of sensing, signaling, and effector responses at DNA doublestrand breaks. DNA Repair (Amst.). 9, 1299-1306 (2010). 